\title{
AVALIAÇÃO DO COMPORT AMENT O DE FRENTE DE CONTAMINAÇÃO EM FUNÇÃO DOS DIFERENTES VALORES DOS COEFICIENTES DE DISPERSIVIDADE
}

\author{
BEHAVIORASSESSMENT OFCONTAMINATION PLUME CONSIDERING \\ DIFFERENT DISPERSIVITYCOEFFICIENTVALUES \\ ANÁLISIS DEL COMPORTAMIENTO DEL FRENTE DE CONTAMINACIÓNEN \\ FUNCIÓN DE LOS DIFERENTES VALORES DE COEFICIENTES DE \\ DISPERSIVIDAD
}

\author{
Janaina Barrios Palma ${ }^{1}$
}

Lázaro Valentin Zuquette ${ }^{1}$

\begin{abstract}
RESUMO
Este trabalho apresenta os resultados obtidos por simulações numéricas utilizando o programa Visual Modflow para a área do lixão da cidade de Poços de Caldas (Estado de Minas Gerais, Brasil). Inicialmente, a área foi investigada e caracterizada em termos geológicos, geotécnicos, hidrogeológicos e climáticos. A partir destas características as escalas das heterogeneidades foram avaliadas e diferentes valores de coeficientes de dispersividade foram obtidos, e associados a tipos de fontes de poluentes em 11 cenários. Os resultados de cada simulação foram analisados frente aos dados obtidos por métodos geofísicos e trabalhos de campo. A simulação que considerou as menores diferenças entre valores de dispersividade vertical e horizontal para as diferentes camadas e os coeficientes de sorção segundo Langmuir foi a que apresentou melhor compatibilidade. Os valores de dispersividade longitudinal e das razões entre as dispersividades longitudinal, vertical e horizontal não afetaram, como esperado, as dimensões da frente de contaminação. Portanto as investigações geológico-geotécnicas possibilitam a avaliação do grau de heterogeneidade da área, e conseqüentemente a adoção de parâmetros de dispersividade muito adequados para a simulação de transporte de poluentes.

Palavras-chave: Modelagem, dispersividade, Poços de Caldas, Minas Gerais, Brasil.
\end{abstract}

1 Departamento de Geotecnia, Escola de Engenharia de São Carlos. 
PALMA, J. B.; ZUQUETTE, L. V. Avaliação do comportamento de frente de contaminação em...

\section{SUMMARY}

This paper presents the results from numeric simulations using the Visual Modflow software for the uncontrolled landfill of Poços de Caldas area (State of Minas Gerais, Brazil). Geological, geotechnical, hydrogeological and climatic investigations were carried out for the area characterization. From these attributes the heterogeneity levels were assessed, and different dispersivity coefficient values were obtained. Based on these data and types of sources of pollutant, 11 sceneries were simulated. The results from each scenario were compared with the geophysical and field data for conformity analysis. The results from scenario 4 which considered vertical and horizontal dispersivity values with smaller differences among scenarios, showed good agreement with the geophysical and field data. The geometry and dimensions of the contamination plume did not change significantly with different dispersivity values considered for the area. Therefore the appropriate geologicalgeotechnical investigations allow for an adequate assessment of the heterogeneity characterization of the area and consequently a good approach of the dispersion parameters.

Key-words: Modelling, dispersivity, Poços de Caldas, Minas Gerais, Brazil.

\section{RESUMEN}

Este trabajo presenta los resultados alcanzados por simulaciones numéricas para el área del relleno sanitario de la ciudad de Poços de Caldas (Estado de Minas Gerais, Brasil), utilizando el programa Visual Modflow. Fueron aplicados diferentes valores de coeficientes de dispersividad considerando las condiciones geológicas, geotécnicas, hidrogeológicas y climáticas. Con base en estas informaciones y con los tipos de fuentes de polución, 11 escenarios fueron creados. Los resultados de cada simulación fueron analizados y confrontados con los resultados provenientes de los métodos geofísicos y trabajos de campo. La simulación (4) que consideró mejor homogeneidad entre valores de dispersividad vertical y horizontal fue la que presentó mejor compatibilidad. La geometría y dimensión de la pluma de contaminación no muestran alteraciones significativas con la aplicación de diferentes valores de dispersividad.

Palabras-clave: Modelos numéricos, dispersividad, Poços de Caldas, Minas Gerais, Brasil.

\section{INTRODUÇÃO}

Os resíduos sólidos oriundos de atividades antrópicas têm sido dispostos em diferentes locais, alguns selecionados após estudos geológicos geotécnicos, e outros simplesmente dispostos sem estudos prévios que poderiam avaliar a adequabilidade do meio físico. A contaminação das águas superficiais, subsuperficiais e dos materiais geológicos (rochas e materiais inconsolidados) é um dos problemas ambientais relacionados aos locais de disposição de resíduos em maior volume. Neste sentido, é fundamental conhecer o comportamento do fluxo de líquidos na área em termos de direção, velocidade e das suas relações com os materiais geológicos como a sorção e os parâmetros hidrodinâmicos, para prever as extensões que podem ser afetadas, e com que intensidades. A dispersão hidrodinâmica é um dos mecanismos responsáveis pelo espalhamento da frente (pluma) de contaminação e é composto pela dispersão mecânica, que é função do coeficiente de dispersividade e da velocidade linear média, e pela difusão molecular efetiva, que é função da tortuosidade e da difusão molecular. A dispersividade é um dos parâmetros mais difíceis de ser obtido, pois é dependente da escala, do grau de heterogeneidade e anisotropia do meio físico. Estudos voltados ao transporte de poluentes considerando diferentes parâmetros de dispersividade podem ser desenvolvidos com modelagem numérica, que é uma ferramenta muito utilizada para simular condições naturais e auxiliar na previsão das mudanças decorrentes de alterações nos componentes do sistema natural. 
PALMA, J. B.; ZUQUETTE, L. V. Avaliação do comportamento de frente de contaminação em...

O presente trabalho aplica a modelagem numérica para avaliar o comportamento da frente dos poluentes considerando diferentes valores do coeficiente de dispersividade para a área do Lixão do município de Poços de Caldas no Estado de Minas Gerais, Brasil (em atividade desde 1985). A área é utilizada sem que estudos geológico-geotécnicos tenham sido realizados para avaliar as condições da área frente à finalidade.

Foram utilizados o modelo "USGS Modular 3D Finite Difference Groundwater Flow Model" (Modflow) descrito por McDonald \& Harbaugh (1988) e o "Modular 3D Finite Difference Mass Transport Model" (MT3D) proposto por Zheng (1992). As principais vantagens observadas nestes programas em relação a outros disponíveis no meio técnico são: a rapidez e facilidade para simular diferentes cenários após a definição do modelo conceitual, a boa interação com o usuário, atualização constante do programa e o grau de compatibilidade com um grande numero de outros softwares (Olsthoorn 1999, Winston 1999). As principais limitações do programa referem-se à consideração somente do fluxo em zona saturada e a não representação dos materiais geológicos em camadas não contínuas. No caso específico do Lixão de Poços de Caldas, a base dos resíduos tem interação direta com a zona saturada e as camadas podem ser consideradas contínuas para a extensão considerada na simulação.

O programa Modflow considera uma situação mais próxima à natural quanto aos tensores de dispersão hidrodinâmica, pois utiliza os valores de dispersão na forma proposta por Burnett \& Frind (1987), permitindo avaliar os parâmetros de dispersividades transversais, além da dispersividade vertical e horizontal (Dxx, Dyy, Dzz, Dxy, Dxz e Dzy). Estes parâmetros são considerados no programa na forma de dispersividade longitudinal, razão entre a dispersividade longitudinal e as dispersividades horizontais e verticais. Como não há dados precisos para os materiais geológicos da área foram simuladas situações considerando valores das relações de dispersividade obtidos por relações empíricas e de similaridade. Valores de dispersividade longitudinal apresentados por Gelhar et al (1985), e Gelhar et al (1992) variam desde $1 \mathrm{~mm}$ a superiores a $1000 \mathrm{~m}$, para distâncias menores que $0,1 \mathrm{~m}$ até maiores que $100 \mathrm{Km}$.

A dispersão hidrodinâmica é responsável pelo espalhamento de contaminantes, e conseqüentemente a sua diluição, que ocorre durante o transporte em meio natural poroso, sendo função da variação da velocidade de percolação, devido às seguintes condições:

1. Diferentes velocidades no interior dos poros, sendo maior no centro do que próximo às paredes;
2. Devido às diferentes características dos materiais geológicos em termos de condutividade hidráulica;

3. Em função das diferentes trajetórias de fluxo;

4. Diferentes tamanhos dos vazios (poros) e sua distribuição;

5. Características químicas (intrínsecas) dos contaminantes;

6. Diferentes concentrações do contaminante e sua distribuição.

Assim, a dispersão hidrodinâmica é a soma da dispersão mecânica (que é função da velocidade linear média de percolação e da dispersividade do meio poroso) e da difusão molecular efetiva (depende das concentrações e da tortuosidade do meio poroso).

Assim, o processo de dispersão depende da escala na qual se considera o processo, e pode ocorrer como micro ou macro dispersão.

O fluxo de massa por dispersão mecânica pode ser avaliado como um processo Fickiano, sendo:

$$
F d=-D d \frac{\partial c}{\partial x}
$$

Onde,

Dd: coeficiente de dispersão mecânica;

Fd: fluxo (mg/s. $\left.\mathrm{m}^{2}\right)$.

O coeficiente de dispersão mecânica é função do coeficiente de dispersividade do meio poroso $(\alpha)$ e da velocidade de percolação média $(\mathrm{V})$, então (Freeze \& Cherry 1979):

$$
D_{d} d=\mathrm{d} \cdot V
$$

Em meios porosos naturais, predominam aspectos espaciais que os caracterizam como heterogêneos e anisotrópicos, portanto a dispersão é um processo em 3 dimensões, que pode ser apresentado por um tensor com nove termos. Burnett \& Frind (1987) simplificam estes aspectos e consideram 3 valores: a dispersividade longitudinal, a dispersividade transversa horizontal e vertical, e para tanto assumem que a condição de dispersividade isotrópica pode ser aplicada para os meios geológicos porosos.

Assim, o coeficiente de dispersividade longitudinal é coincidente com a direção do fluxo, o coeficiente de dispersividade transverso horizontal é normal à direção do fluxo, mas paralelo à superficial da Terra e o coeficiente de dispersividade transverso vertical é normal ao fluxo e perpendicular à superfície da Terra (Knopman \& Voss 1987). 
PALMA, J. B.; ZUQUETTE, L. V. Avaliação do comportamento de frente de contaminação em...

$\mathrm{Na}$ maioria dos programas, os coeficientes de dispersividade são considerados no campo do tensor de dispersão hidrodinâmico, que é a soma da dispersão mecânica com a difusão molecular efetiva. As equações a seguir, apresentadas por Burnett \& Frind (1987) representam o tensor de dispersão hidrodinâmico, assumindo a dispersão isotrópica. Esta condição é a considerada pelo programa Visual Modflow.

$$
\begin{aligned}
& D x x=\alpha_{L} \frac{V^{2} x}{\mid v}+\alpha_{I H} \frac{V^{2} y}{|v|}+\alpha_{I V} \frac{V^{2} z}{|v|}+D^{*} \\
& D y y=\alpha_{L} \frac{V^{2} y}{\eta \mid}+\alpha_{T H} \frac{V^{2} x}{\mid v}+\alpha_{I V} \frac{V^{2} z}{|\eta|}+D^{*} \\
& D_{z z}=\alpha_{L} \frac{V^{2} z}{\mid y^{2}}+\alpha_{I H} \frac{V^{2} x}{v \mid}-\alpha_{J V} \frac{V^{2} y}{v}+D^{*}
\end{aligned}
$$

$$
\begin{aligned}
& I x y=D y x=\left(\alpha_{2}-\alpha_{T I L}\right) \frac{V_{x} V_{y}}{|\eta|} \\
& I)_{x z}=I_{z x}=\left(\alpha_{2}-\alpha_{T V}\right) \frac{V x V z}{v} \\
& I y_{z}=D z y=\left(\alpha_{1},-\alpha_{T V}\right) \frac{V y V z}{v}
\end{aligned}
$$

Sendo:

$\alpha_{\mathrm{L}}$ : dispersividade longitudinal;

$\alpha_{T}$ : dispersividade transversal;

$\alpha_{\mathrm{Th}}$ : dispersividade transversal horizontal;

$\alpha_{\mathrm{TV}}$ : dispersividade transversal vertical;

$D^{*}$ : Coeficiente de difusão molecular efetivo;

Vx, Vy, Vz: Componentes das velocidades de percolação;

$|v|=\left(X^{2} x+V^{2} y+V^{2} z\right) 1 / 2$ vetor de magnitude de velocidade.

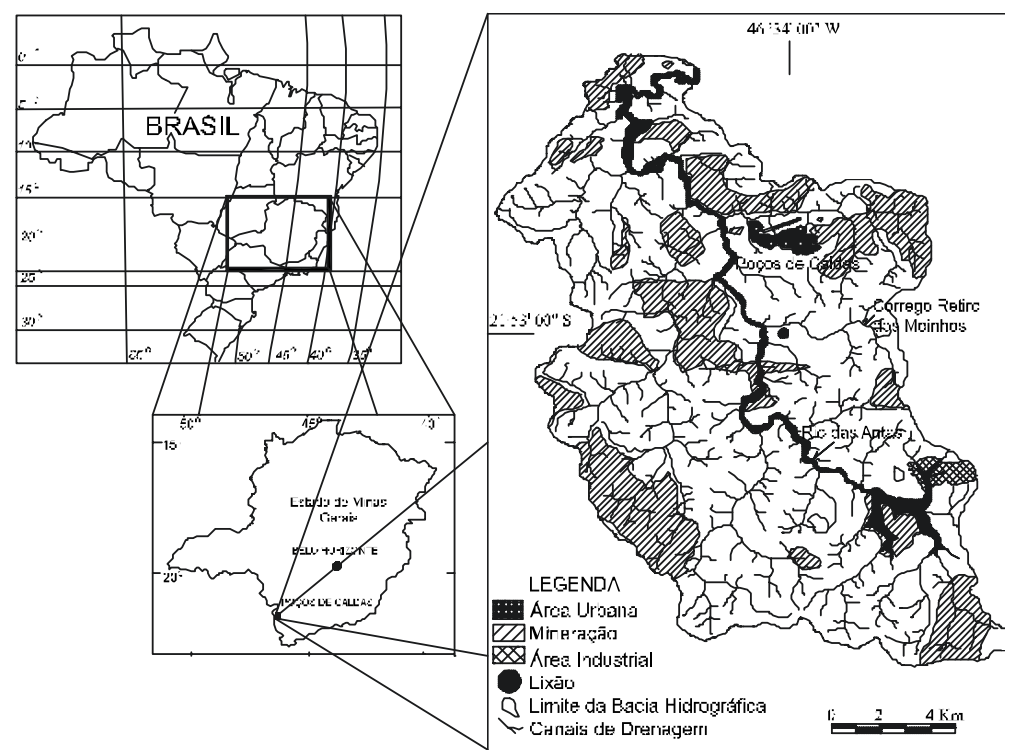

Figura 1 - Localização da área em estudo, usos e ocupações da Bacia do Rio das Antas. 
PALMA, J. B.; ZUQUETTE, L. V. Avaliação do comportamento de frente de contaminação em...

\section{CARACTERÍSTICAS GERAIS DA ÁREA}

A área estudada tem como coordenadas geográficas de referência $46^{\circ} 34^{\prime} 00^{\prime \prime}$ de longitude Oeste e $21^{\circ}$ 53' 00"de latitude Sul, à margem do córrego do Retiro dos Moinhos, na bacia do Rio das Antas, e distante 12 $\mathrm{Km}$ da área urbana de Poços de Caldas, próxima à rodovia que liga as cidades de Poços de Caldas à Andradas (figura 1).

Segundo os critérios de Köppen o clima é do tipo Cwb, situando-se entre o grupo A, dos tropicais quentes e o grupo $\mathrm{C}$ dos mesotérmicos, com inverno seco e verão chuvoso. A precipitação média anual é de $1.700 \mathrm{~mm}$, a temperatura média anual é de $18^{\circ} \mathrm{C}$, a umidade relativa média anual é $76.5 \%$, a evapotranspiração real média anual igual a $850 \mathrm{~mm}$ e a direção preferencial dos ventos é $\mathrm{N}-\mathrm{NE}$.

\section{Substrato Rochoso}

As litologias que constituem a bacia hidrográfica do Córrego Retiro dos Moinhos são essencialmente nefelina-sienitos e fonolitos (figura 2). Os fonolitos são variados, com predomínio dos egerina-fonolito, fonolitos porfíros e pseudoleucita-fonolitos. A textura dos fonolitos varia de afanítica a fanerítica fina ou, raramente fina média e a coloração varia de cinza esverdeado a preto. Mineralogicamente são constituídos por nefelina e em menor proporção por analcima e sodalita; os piroxênios ocorrem em porcentagens que podem atingir até $20 \%$, enquanto os anfibólios são menos freqüentes.

Os nefelina sienitos apresentam estrutura maciça, são leucocráticos, constituídos predominantemente por nefelina e ortoclásios, e os minerais máficos (piroxênios, biotitas e acessórios) atingem no máximo $10 \%$ do total dos minerais da rocha.

\section{Materiais Inconsolidados}

Os materiais inconsolidados da área foram classificados em quatro tipos quanto à gênese e de acordo com a proposta da Geological Society (1990): os materiais retrabalhados, reliquiares, residuais e materiais de aterro (figura 3).

Os materiais retrabalhados estão associados aos talvegues dos principais canais de drenagem, sendo representados por aluviões e colúvios. O material residual é oriundo da alteração das rochas sotopostas e apresentase com alto grau de heterogeneidade, guardando poucas características da rocha original. Os materiais reliquiares mantêm as características texturais e estruturais das rochas, apresentam espessuras de até $10 \mathrm{~m}$. A camada de material do aterro ocorre nas áreas onde foi explorado o minério de alumínio (bauxita) até profundidades da ordem de 4 metros, e suas cavas foram aterradas com blocos e materiais inconsolidados não aproveitados como minério ou materiais retirados de outras áreas. A figura 4 mostra a distribuição vertical dos materiais inconsolidados (alinhamento A-B, representado na figura 3).

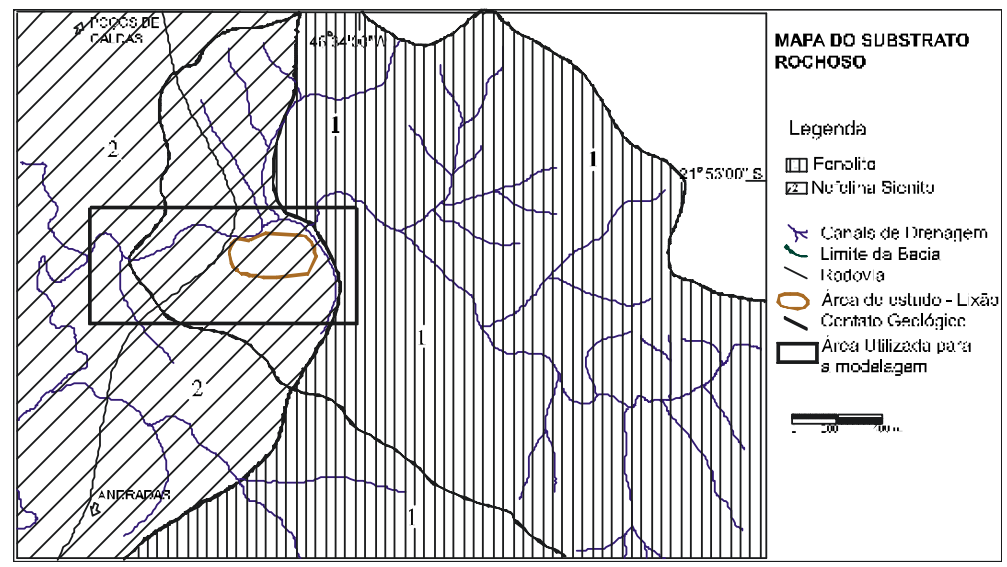

Figura 2 - Mapa do Substrato Rochoso - posicionamento do lixão e área utilizada para a modelagem. 


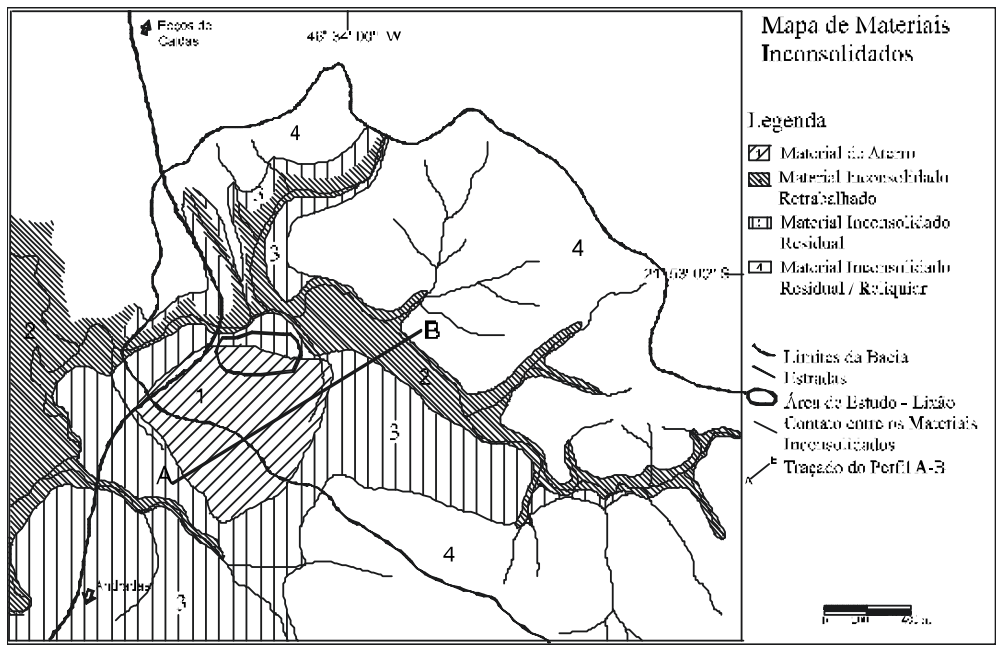

Figura 3 - Mapa de Materiais Inconsolidados

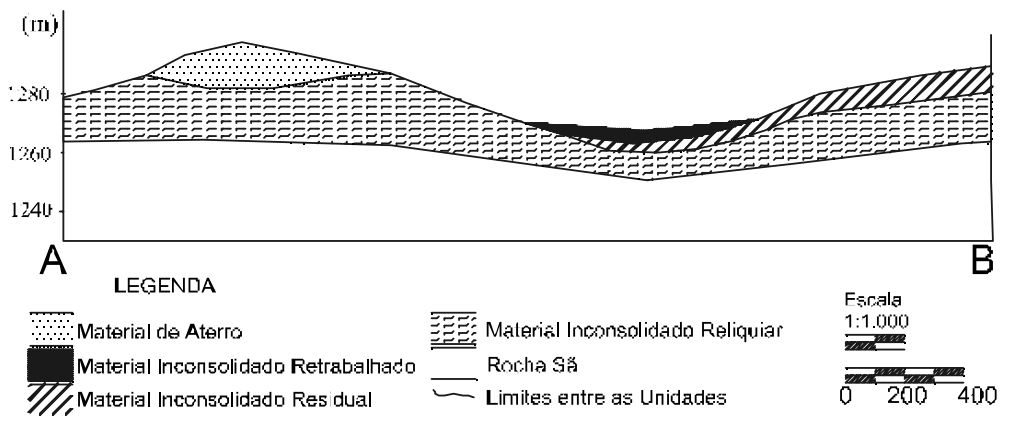

Figura 4 - Seção estratigráfica representando a distribuição vertical dos materiais inconsolidados. 
PALMA, J. B.; ZUQUETTE, L. V. Avaliação do comportamento de frente de contaminação em...

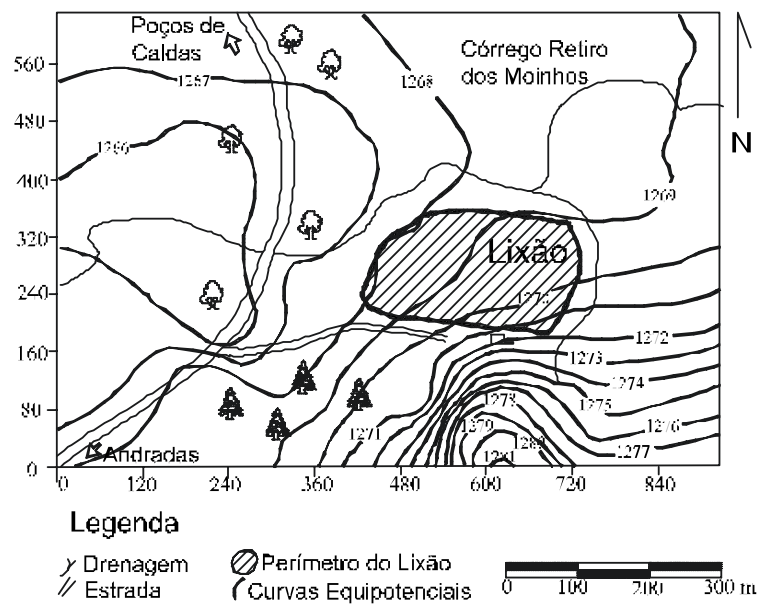

Figura 5 - Mapa de Fluxo Subsuperficial (Elis 1998).

Foram realizados ensaios químicos em amostras deformadas retiradas, a cada $50 \mathrm{~cm}$, até a profundidade, de $11 \mathrm{~m}$ e revelaram valores de $\mathrm{pH}$ entre 6 e 8 , capacidade de troca catiônica inferiores a $5 \mathrm{cmol}(+) / \mathrm{Kg}$ de material e superfície específica menores que $50 \mathrm{~m}^{2} / \mathrm{g}$.

\section{Características Hidrogeológicas}

Sondagens Elétricas Verticais (SEV), Caminhamento elétrico dipolo-dipolo e Sondagens Dipolares, desenvolvidos por Elis (1998) associadas a observações de campo auxiliaram na elaboração do mapa de fluxo subsuperficial (figura 5 ).

As SEVs definiram a camada de resíduos, com resistividades entre 5,6 e 11,2 ohm.m, uma camada com resistividades entre 25 e 87 ohm.m, interpretada como solo saturado na base do aterro e uma camada de alta resistividade (maior que $1450 \mathrm{ohm} . \mathrm{m}$ ) interpretada como saprolito ou sienito alterado. As sondagens dipolares indicaram que a base dos resíduos está em interação direta com a zona saturada. Os resultados dos ensaios de caminhamento elétrico na forma de mapas de resistividade aparente mostram uma evolução da frente de contaminação entre 2 medidas realizadas com 850 dias de diferença.

A recarga estimada para a área é de $340 \mathrm{~mm} / \mathrm{ano}$, que equivale a $20 \%$ da precipitação total, está condicionada às características de condutividade hidráulica ele- vada do material inconsolidado superficial e dos resíduos, a baixa declividade (menor que $4 \%$ ) e às feições superficiais armazenadoras que impedem o escoamento superficial, aumentando o tempo de permanência das águas na superfície e, portanto, o volume infiltrado.

\section{CARACTERÍSTICAS DO LIXÃO}

Os resíduos urbanos e hospitalares gerados no município de Poços de Caldas são dispostos, neste local desde 1985 e, atualmente, são depositadas 60 toneladas/dia de resíduos urbanos residenciais, 5 toneladas/dia de resíduos decorrentes dos serviços da saúde, e 15 toneladas/dia de material proveniente das indústrias comuns e do comércio. A área ocupa $33.000 \mathrm{~m}^{2}$ com volume aproximado de $250.000 \mathrm{~m}^{3}$, e espessura média de $7.5 \mathrm{~m}$ (figura 6 ).

Os resíduos estão sendo recobertos por uma camada pouco espessa de material argiloso compactado, não existe, porém, nenhum procedimento de controle à poluição.

\section{CONDIÇÕES PARAA SIMULAÇÃO}

Para desenvolver a simulação foi admitida uma área de $1.230 \mathrm{~m}$ de comprimento por $540 \mathrm{~m}$ de largura, como pode ser observada na figura 2. Tais dimensões foram estipuladas no sentido de: 
PALMA, J. B.; ZUQUETTE, L. V. Avaliação do comportamento de frente de contaminação em...

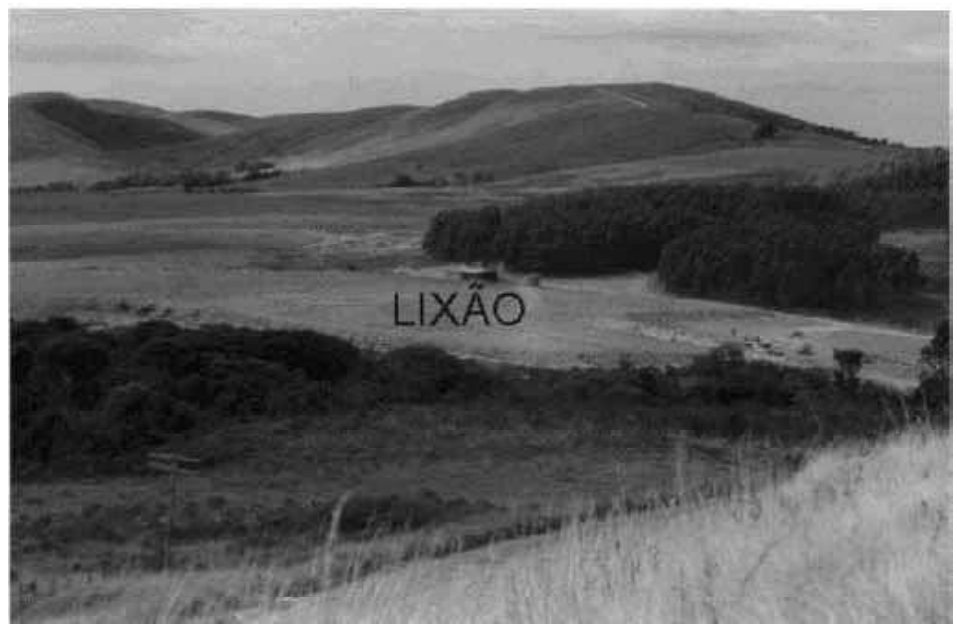

Figura 6 - Vista Geral da Área.

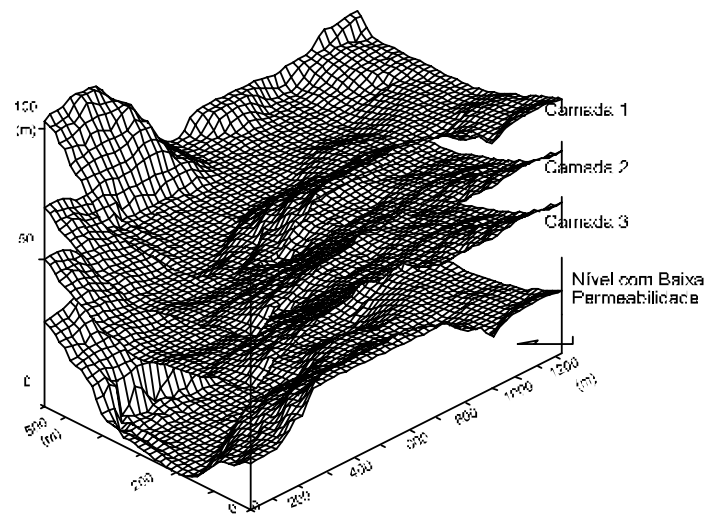

Figura 7 - Representação da geometria das camadas geológicas consideradas na simulação. 
PALMA, J. B.; ZUQUETTE, L. V. Avaliação do comportamento de frente de contaminação em...

1. Avaliar a extensão longitudinal atingida pela frente de contaminação.

2. Na menor dimensão, evitar incluir no modelo áreas de alta declividade que afetariam os resultados, porém, sem que tenha real importância no fluxo dos poluentes a partir da área dos resíduos.

Para a discretização das células, inicialmente, gerou-se uma malha horizontal regular de 82 colunas por 36 linhas, gerando células de $15 \times 15 \mathrm{~m}$, e como dimensão vertical adota-se o valor da espessura de cada camada, para tanto, o pacote de materiais geológicos foi dividido em 3 camadas (figura 7). Esta separação é função, principalmente, dos valores da condutividade hidráulica dos materiais inconsolidados, como pode ser observado na tabela 1. O tempo adotado para a discretização temporal foi de 0 até 7.300 dias (20 anos), com intervalos de 1.825 dias.

\section{Calibração}

Os valores utilizados na calibração foram obtidos a partir do trabalho de Elis (1998), que apresenta a delimitação da frente de contaminação em valores de resistividade elétrica. Para correlacionar estes valores com a concentração de Sólidos Totais Dissolvidos (TDS) foi utilizada a proposta de Meju (2000).

$$
\text { TDS }=-54.4+7.04 \sigma \mathrm{w}
$$

Sendo $\sigma_{\mathrm{w}}$ a condutividade elétrica da solução aquosa em $\mathrm{mS} / \mathrm{m}\left(\sigma_{\mathrm{w}}=1.000 /\right.$ Resistividade) e o TDS em mg/L. A opção por esta expressão foi devido à grande quantidade de dados utilizados como base da correlação e por considerar valores obtidos, também, em lixões localizados em território brasileiro. As figuras $8(A)$ e 8(B) apresentam os valores utilizados na calibração, equivalentes aos tempos de 3.650 e 4.500 dias, respectivamente, e para a profundidade de $10 \mathrm{~m}$, a partir dos resultados apresentados por Elis (1998).

Além das informações utilizadas para a calibração, outros resultados da eletroresistividade foram úteis para o conhecimento da geometria da pluma e a comparação dos resultados das simulações numéricas com a condição natural. Estes resultados não apresentam continuidade temporal, mas delimitam a pluma em termos espaciais, na forma de mapas em diversas profundidades (figura 9) e como perfis longitudinais (figura 10) e ortogonais (figura 11).

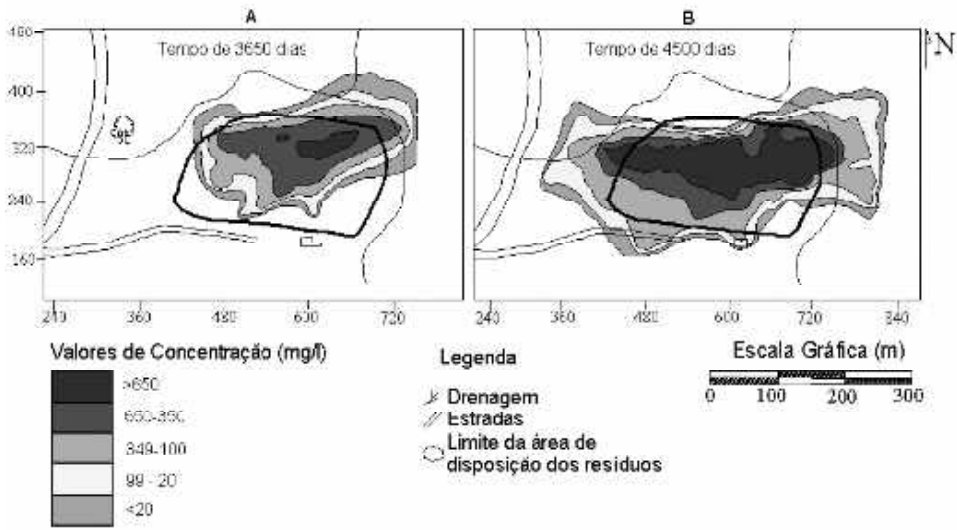

Figura 8 - Delimitação da frente de contaminação a partir de ensaios geofísicos gerados por Elis (1998) para a profundidade de $10 \mathrm{~m}$. (A) - Tempo de 3.650 dias e (B) - Tempo de 4500 dias. 

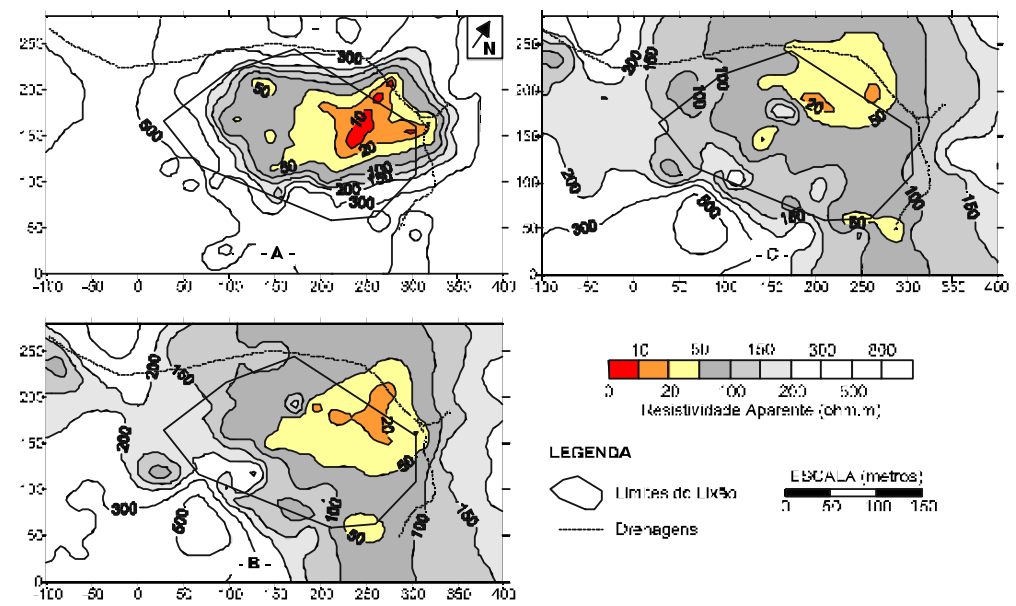

Figura 9 - Delimitação da frente de contaminação a partir de ensaios geofísicos em diversas profundidades (A) $10 \mathrm{~m}$, (B) $20 \mathrm{~m}$ e (C) $30 \mathrm{~m}$, para o tempo de 4.380 dias (Fonte: Elis 1998).

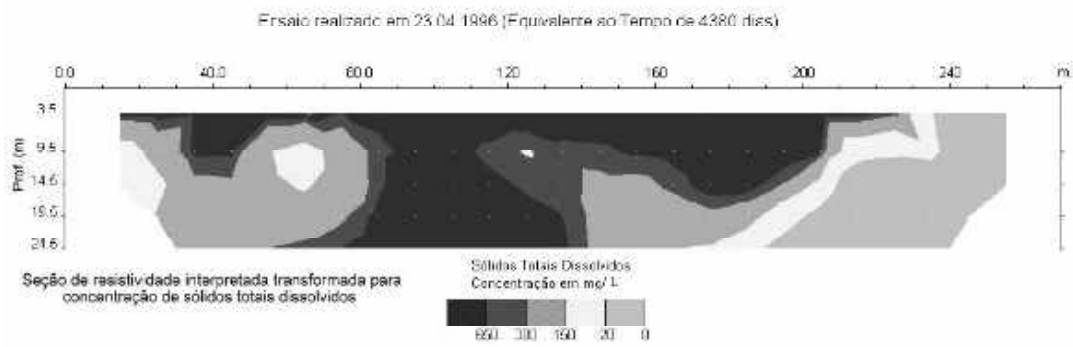

Figura 10 - Delimitação da frente de contaminação a partir de ensaios geofísicos, perfil no sentido leste - oeste (parte tracejada da linha EW na figura 13); do domínio do lixão (Fonte: Elis 1998).

Enseic realizado em 23.041996 (Equivalente ao Tempo de 4380 dias)

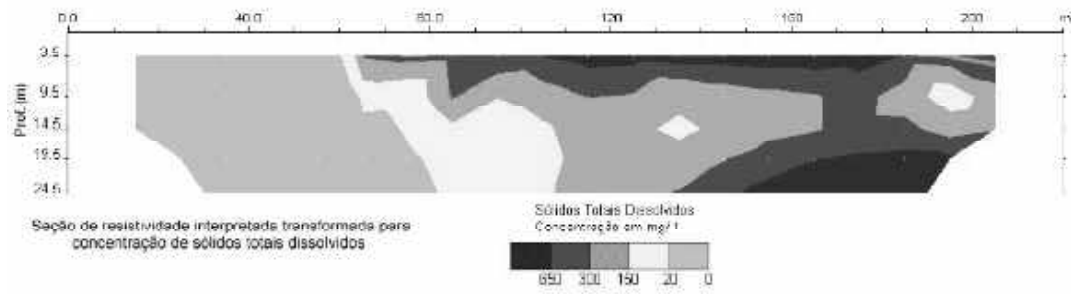

Figura 11 - Delimitação da frente de contaminação a partir de ensaios geofísicos, perfil no sentido norte-sul (parte tracejada da linha E-W na figura 13); do dominio do lixão (Fonte: Elis 1998). 
PALMA, J. B.; ZUQUETTE, L. V. Avaliação do comportamento de frente de contaminação em...

\section{Definição dos Cenários}

Para equacionar os diferentes cenários para a simulação, e obtenção das distâncias e intensidades atingidas pelas frentes de contaminação, considerou-se a área do Lixão constante $\left(33.000 \mathrm{~m}^{2}\right)$ e as informações geológicas - geotécnicas sobre: variações da dispersividade e do tipo de fonte, distribuição espacial dos materiais geológicos, as características físicas dos materiais geológicos que constituem cada camada (massa específica dos sólidos, porosidade efetiva, mineralogia), as características hidráulicas dos materiais geológicos, as características climáticas e de relação com os materiais geológicos (evapotranspiração, recarga). Quanto às características de sorção para os diferentes materiais geológicos foi considerada a isoterma de Langmuir por ser a que melhor representa as características de sorção dos materiais geológicos em condições naturais (Sparks 2001).

As características de dispersividade estão diretamente relacionadas aos materiais geológicos, as anisotropias a partir de relações entre as características espaciais dos materiais inconsolidados, as extensões da área (escala) e as características geológicas geotécnicas dos diferentes materiais geológicos.

Os parâmetros de dispersividade, para a área, baseou-se nos seguintes pontos:

1. Características específicas dos materiais geológicos e distribuição espacial;

2. Grau das descontinuidades entre os diferentes materiais geológicos; e

3. Heterogeneidade de cada material geológico, considerando a presença de macroporos.

No sentido de avaliar as condições da área quanto à macrodispersividade, as três camadas de materiais geológicos foram avaliadas em termos da anisotropia, escala do sistema (dimensões), condutividade hidráulica e fábrica (arranjo dos minerais e vazios). Da análise destas características conclui-se que as camadas 1e 2 são muito semelhantes, e para tais condições a escala do sistema pode ser considerada da ordem de 3 a $15 \mathrm{~m}$, enquanto para a camada 3 foi estimado de $2 \mathrm{~m}$ ou menor.

Considerando a proposta de Neuman (1990) que foi gerada a partir dos dados de Gelhar et al (1992) como:

$\alpha \mathrm{L}=0.0169 \mathrm{x}^{1.53}$ (válida para $\mathrm{x} \leq 100 \mathrm{~m}$ )

sendo:

$\alpha \mathrm{L}$ - Coeficiente de dispersividade longitudinal (m). $\mathrm{x}$ - Escala do sistema (comprimento em $\mathrm{m}$ ).
Foram obtidos para as camadas 1 e 2 coeficientes de dispersividade longitudinal de 0,1 e $1 \mathrm{~m}$, e para a camada 3 de $0,05 \mathrm{~m}$. A camada 1 e 2 apresentam variações em termos de lentes ou subcamadas com pequena extensão lateral que ocorrem em grandezas ( $x$ e y) da ordem de 3 a $15 \mathrm{~m}$. Estas são decorrentes do processo de intemperismo que atuou sobre o material rochoso e, também, devido a variabilidade sazonal do nível de água. A camada 3 apresenta variações também, decorrentes do processo de intemperismo, porém como mantém a característica isovolumétrica as mesmas refletem a heterogeneidade da litologia em escalas inferiores a $2 \mathrm{~m}$.

A partir das propostas de Gelhar et al. (1992) foram adotados para as razões entre dispersividade horizontal e longitudinal de 0,1 e para dispersividade vertical longitudinal de 0,01 . Os coeficientes foram utilizados pelos seguintes aspectos:

1 - Os valores de escala do sistema, para este caso, estão dentro da faixa considerada de alta confiabilidade pelos autores (2 a 100m);

2 - As razões entre dispersividades têm sido usadas em diversos estudos com simulações numéricas, assim como por enquadrar-se, também, na faixa de alta confiabilidade.

Quanto às características referentes à dinâmica da concentração de poluentes nas fontes, 3 condições básicas foram consideradas:

1 - O Lixão como uma fonte de poluentes contínua e com concentração constante, mas que a carga total de poluentes a ser transportada depende da interação da fonte com o meio aquoso. Desta forma a carga total percolada não está definida a priori, sendo controlada pelas condições do meio em termos das características hidráulicas e climáticas.

2 - Adota como fonte que condiciona um volume de líquido e uma carga pré-definida de poluentes. Ou seja, a injeção de poluentes no meio aquoso é constante ao longo de um período de tempo; e neste caso relacionado à taxa de recarga a partir da pluviosidade $\mathrm{e}$ das condições de infiltração.

3 - Que o Lixão é uma fonte com concentração variável com o tempo, e crescente com uma taxa pré-definida. Neste caso, deve-se considerar parte das condições anteriores, a saber:

1 -A concentração varia crescentemente com o tempo, mas a carga total depende da interação com o meio aquoso. 
PALMA, J. B.; ZUQUETTE, L. V. Avaliação do comportamento de frente de contaminação em...

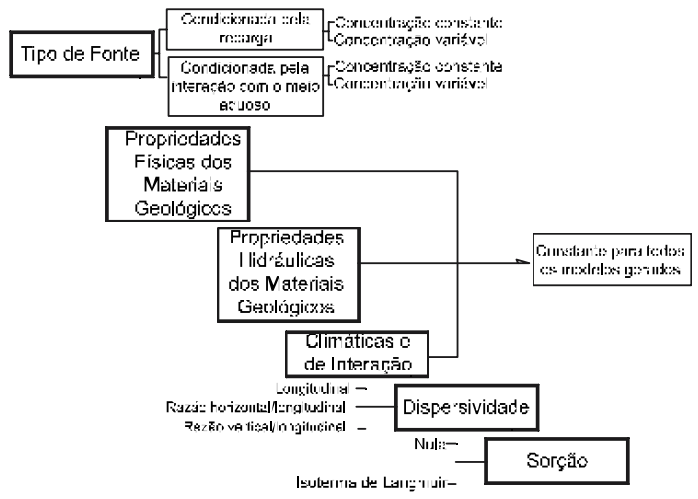

Figura 12 - Seqüência utilizada para a definição dos cenários.

2 - A concentração varia crescentemente, mas sempre associada a um volume de líquido constante com o tempo, representado pela recarga.

Estas condições permitem definir cenários que representem a variabilidade dos materiais geológicos anisotrópicos, os parâmetros de dispersividade e de sorção dos materiais geológicos da área em questão; assim como as condições de concentrações dos poluentes. A partir destes itens, os cenários foram definidos de acordo com a seqüência da figura 12 .

No total foram simulados 11 cenários, considerando os diferentes valores de coeficiente de dispersividade longitudinal e tipos de fontes.

\section{Cenário Básico}

A partir das características hidráulicas dos materiais geológicos e de pontos de calibração, foram simuladas as condições de fluxo das águas na zona saturada. A figura 13 representa as linhas de equipotenciais em planta para a camada 1 e os vetores indicando direção de fluxo e magnitude. Na figura 14 observa-se um perfil na direção $\mathrm{E}-\mathrm{W}$, na posição central da área (posição de $325 \mathrm{~m}$, representada na figura 13 ), onde se observam as linhas equipotenciais e os vetores, indicando as direções de fluxo e a magnitude associada. Nota-se mudanças de magnitude em relação às diferentes camadas de materiais geológicos, de acordo com as características hidráulicas.
Os resultados obtidos pela simulação foram comparados com os dados gerados via geofísica e observados em campo, e apresentam boa compatibilidade. Estes resultados foram adotados como o componente advecção para os outros cenários, associados à dispersão e à sorção.

Cenário 1 - Considerou-se a fonte com concentração constante e que a carga total dos poluentes é função da interação entre a fonte e o meio aquoso, e o transporte dos poluentes somente por advecção e dispersão. Os valores utilizados para Dispersividade Longitudinal $(\mathrm{m})$ foram de $0,1 \mathrm{~m}$ para a camada 1 e 2 e de 0,05 para a camada 3 , e Razão entre Dispersividade Horizontal e Longitudinal de 0,1 para as camadas 1 e 2 e de 0,01 para a camada 3 e a Razão entre Dispersividade Vertical e Longitudinal de 0,01 para as camadas 1 e 2 e de 0,001 para a camada 3 .

Cenário 2 - Simulou-se fonte com concentrações variáveis, crescentes, em 5 níveis, conforme a tabela 2. Adotou-se que o transporte dos poluentes ocorre por advecção e dispersão. Como no cenário 1, a carga total de poluentes é função da interação do meio aquoso com a fonte.

Cenário 3 - Semelhante ao cenário 1, porém com parâmetros de dispersividades diferentes, sendo que a Dispersividade Longitudinal $(\mathrm{m})$ foi de $0,1 \mathrm{~m}$ para a camada 1 e $1.0 \mathrm{~m}$ para a camada 2 e de 0,5 para a camada 3, e Razão entre Dispersividade Horizontal e longitudinal de 0,1 para as camadas 1 e 2 e de 0,01 para a camada 3 e a Razão entre Dispersividade Vertical e lon- 
PALMA, J. B.; ZUQUETTE, L. V. Avaliação do comportamento de frente de contaminação em...

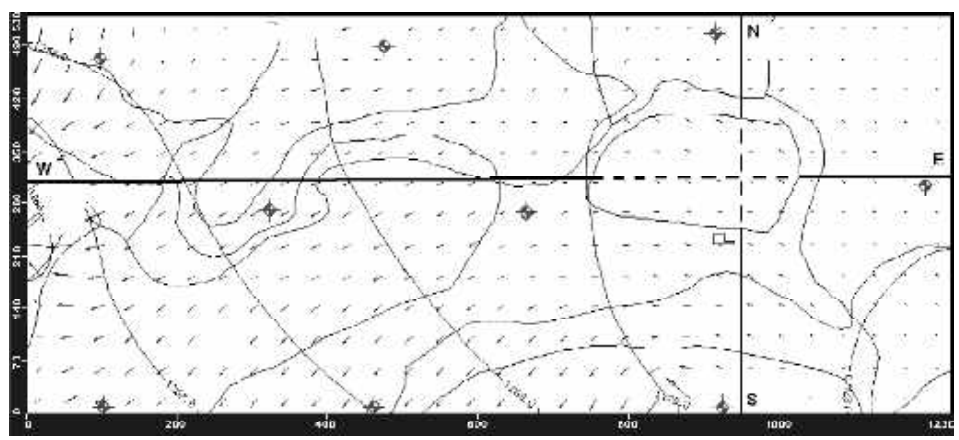

Figura 13 - Linhas equipotenciais, direções de fluxo e posições da linha base (NS) e (EW) consideradas para os perfis (parte tracejada indica local dos caminhamentos de geofísica).

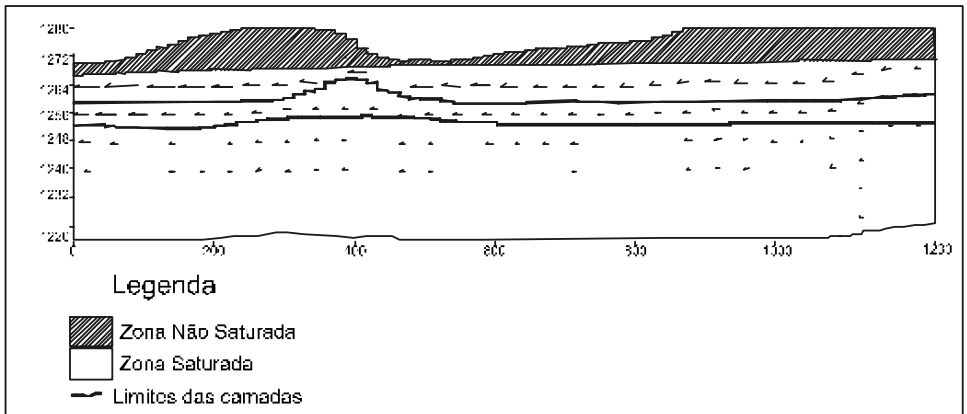

Figura 14 - Seção longitudinal subparalela ao fluxo com a magnitude de fluxo em relação às camadas 1, 2 e 3 (coincidentes com E-W).

gitudinal de 0,01 para as camadas 1 e 2 e de 0,001 para a camada 3. Os parâmetros de dispersividade, neste caso, buscam refletir uma heterogeneidade vertical mais acentuada do que no cenário 1 .

Cenário 4 - Quanto à fonte e à dispersividade as condições são semelhantes as do cenário 1 , porém as de sorção são controladas pela Isoterma de Langmuir, que representa mais adequadamente as condições dos materiais geológicos com o tempo. Os parâmetros da Isoterma de Langmuir adotados são valores médios considerando uma composição química ampla, representando o total de sólidos dissolvidos sendo $\alpha=0.04016$ $\mathrm{m}^{3} / \mathrm{kg}$ e $\beta=2.8 .10^{-4}-\mathrm{Kg} / \mathrm{Kg}$.

Cenário 5 - Representa uma fonte onde a carga total de poluente está associada a um volume de líqui- do constante (recarga). Os outros parâmetros são iguais aos considerados no cenário 1 .

Cenário 6 - Caracterizado por uma variação da concentração ao longo do tempo conforme seqüência da tabela 2, porém sempre relacionando a um volume constante de líquidos equivalente a recarga. Os demais parâmetros são iguais aos do Cenário 2.

Cenário 7 - As condições de fonte são semelhantes as do cenário 5 , porém os parâmetros de dispersão representam um meio geológico com heterogeneidade vertical mais intensa do que os do cenário 5 .

Cenário 8 - Fonte semelhante ao cenário 5 , enquanto os parâmetros de dispersividade e de sorção são iguais ao do cenário 4 . 
PALMA, J. B.; ZUQUETTE, L. V. Avaliação do comportamento de frente de contaminação em...

Cenário 9 - Neste cenário combinaram-se as condições de fonte do cenário 2 e os outros parâmetros utilizados para a simulação do cenário 4 .

Cenário 10 - Considerou a maioria dos parâmetros como no cenário 1 , no entanto os coeficientes de dispersividade longitudinal foram alterados.

Cenário 11 - Esta situação adotou os mesmos parâmetros do cenário 10 , considerando o parâmetro de sorção do cenário 4.

\section{RESULTADOS E ANÁLISES}

Os resultados obtidos a partir das simulações são gerados na forma de documentos bidimensionais com isolinhas (mapas) e seções ortogonais, em $90^{\circ}$, com a disposição em profundidade dos materiais geológicos, isolinhas e vetores. Os resultados são apresentados de tal maneira que permitam avaliar o comportamento dos poluentes em relação às diferentes características utilizadas na simulação, seja em termos espaciais e/ou temporais.

Os comprimentos e as larguras máximas atingidas pela frente de contaminação estão representados na tabela 3. Na comparação entre os valores de desvio padrão para as camadas 1 e 2 , verifica-se que os valores são mais elevados para a camada 2, o que demonstra que a associação dos valores utilizados de dispersividade e tipos de fonte são mais efetivos para profundidades maiores.

Os cenários 2 e 9 têm o mesmo tipo de fontes, mas apresenta diferenças nos valores de sorção, que foi considerado apenas no cenário 9 , refletindo, basicamente, nas dimensões da frente para a camada 2. 0 tipo de fonte considerada nos cenários $5,6,7$ e 8 (recarga constante - fonte associada a um volume de líquido constante) condiciona tanto em termos de dimensões quanto às grandezas das concentrações (tabelas 3 e 4 e figuras 21 a 26), com valores abaixo dos resultados obtidos pela eletroresistividade e, portanto, não refletindo o comportamento natural. Para estes cenários observa-se que as maiores concentrações estão associadas à porção mais a jusante da área de disposição dos resíduos, gerando uma distribuição para montante e outra para jusante, o que não é compatível com o registro da eletroresistividade, o tipo de fonte e as condições de advecção.

Baseando-se nas formas de distribuição espacial e temporal obtidas pela eletroresistividade em termos de concentração / resistividade aparente, a simulação 4 é a que apresenta resultados com maior compatibilidade com os resultados obtidos via eletroresistividade, ou seja, quando todos os aspectos do transporte são considerados.
A tabela 4 apresenta os valores de concentrações máximas para cada camada, nas diferentes condições de simulação.Verifica-se que o desvio padrão diminui em relação à média com o aumento do tempo, quando consideram as simulações com o mesmo tipo de fonte. Porém, é mais sensível à diminuição para a camada 1 , e menor para a camada 3 .

Observou-se que a distribuição da contaminação em área a partir do topo da segunda camada é muito irregular, formando ilhas de concentração com valores diferentes. Esta condição também foi verificada nos estudos de geofísica, como pode ser observado nas figuras 10 e 11 , e está relacionada à geometria das camadas, aos aspectos da dispersão e de sorção.

Cenário 1 - Como este cenário representa uma condição na qual não se considera o efeito da sorção, o transporte dos poluentes está associado principalmente à advecção e, portanto, os níveis de contaminação são elevados, observa-se que para o tempo de 7.300 dias a 3 camada é atingida pelos poluentes em concentração superiores a $120 \mathrm{ppm}$, como pode ser observado na figura 15 , que representa a seção longitudinal ao lixão (posicionada na figura 13).

Para a camada 1, considerando uma isolinha de $20 \mathrm{mg} / \mathrm{L}$, a frente apresenta para o tempo de 7.300 dias mais de $950 \mathrm{~m}$ de comprimento e 350 de largura. Para a camada 2, considerando a isolinha de $5 \mathrm{ppm}$, atinge a largura de $354 \mathrm{~m}$ e $892 \mathrm{~m}$ de comprimento. A camada 3 , para o mesmo tempo e para a isolinha de $0,2 \mathrm{ppm}$, apresenta comprimento de $615 \mathrm{~m}$ e largura de $130 \mathrm{~m}$. O topo da camada 3 é atingido por concentrações acima de $70 \mathrm{ppm}$ no tempo de 1.825 dias e atinge $170 \mathrm{ppm}$ em 7.300 dias (figura 16).

Cenário 2 - Para este caso as condições de sorção, também não foram consideradas e a camada 3 é afetada por concentrações da ordem de 150 ppm para o tempo de 7.300 dias. O comprimento e a largura para as isolinhas mínimas $(20,5$ e $0,2 \mathrm{mg} / \mathrm{L})$ para as camadas 1,2 e 3 são $684 \mathrm{~m}$ e $275 \mathrm{~m}, 691 \mathrm{~m}$ e $288 \mathrm{~m}$ e $370 \mathrm{~m}$ e $177 \mathrm{~m}$, respectivamente. Em relação à profundidade, para o tempo de 7.300 dias as concentrações não diferem muito dos valores do Cenário 1 , mas há diferenças significativas para os tempos menores.

Em relação ao cenário 1, observa-se que a frente, para a mesma concentração, avança a distâncias menores, porém quando a fonte atinge valores iguais ou maiores que 600ppm existe uma rápida compensação que é compatível com a teoria, quando consideram-se longos períodos de tempo. As figuras 17 e 18 ilustram os perfis com a evolução da frente de contaminação referentes aos tempos de 1.825 e 7.300 dias, respectivamente. 
PALMA, J. B.; ZUQUETTE, L. V. Avaliação do comportamento de frente de contaminação em...

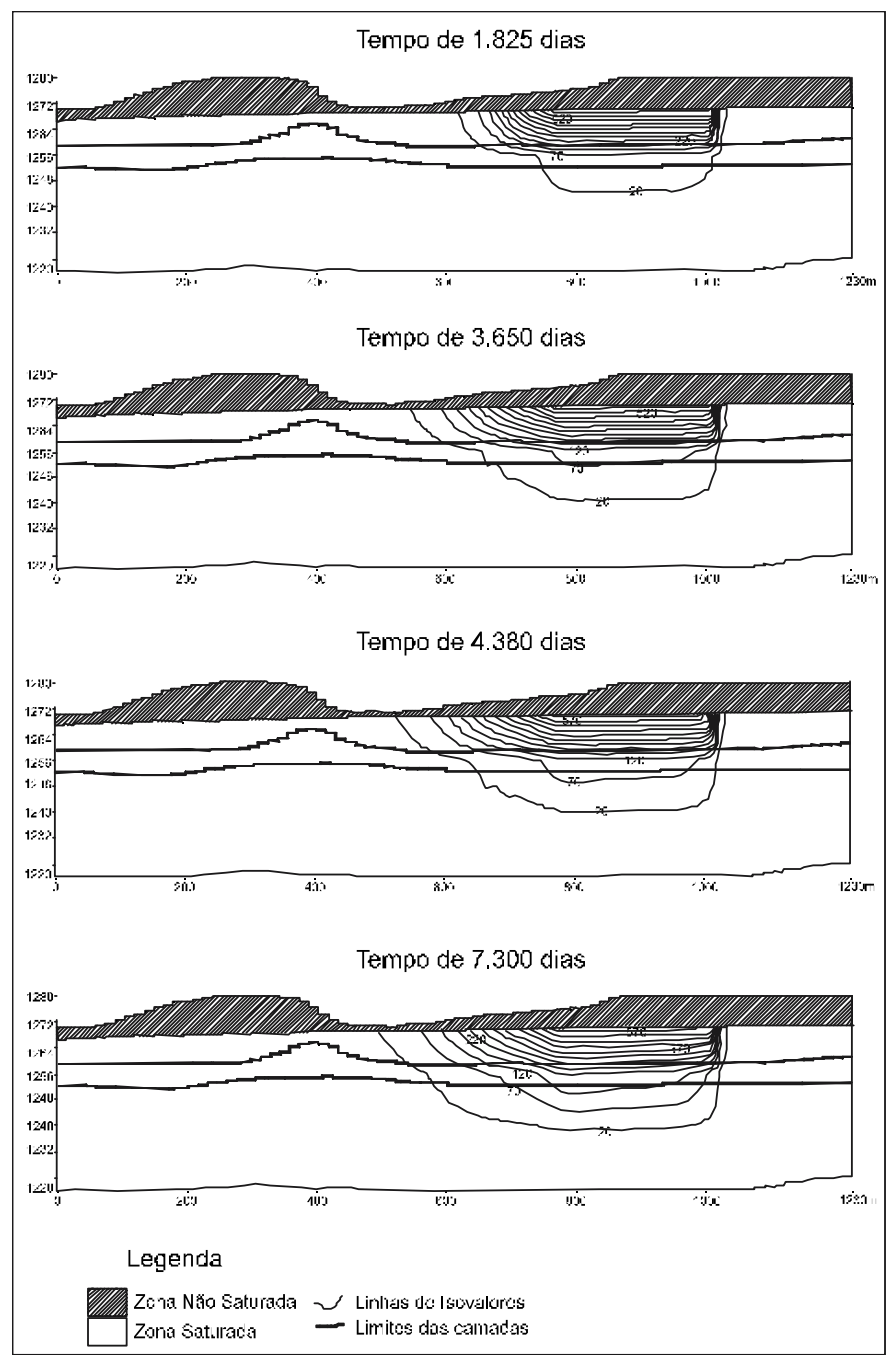

Figura 15 - Seção longitudinal ao Lixão representando a distribuição da frente de contaminação nos diversos tempos simulados para o Cenário 1 (Posição do perfil mostrado na figura 13). 

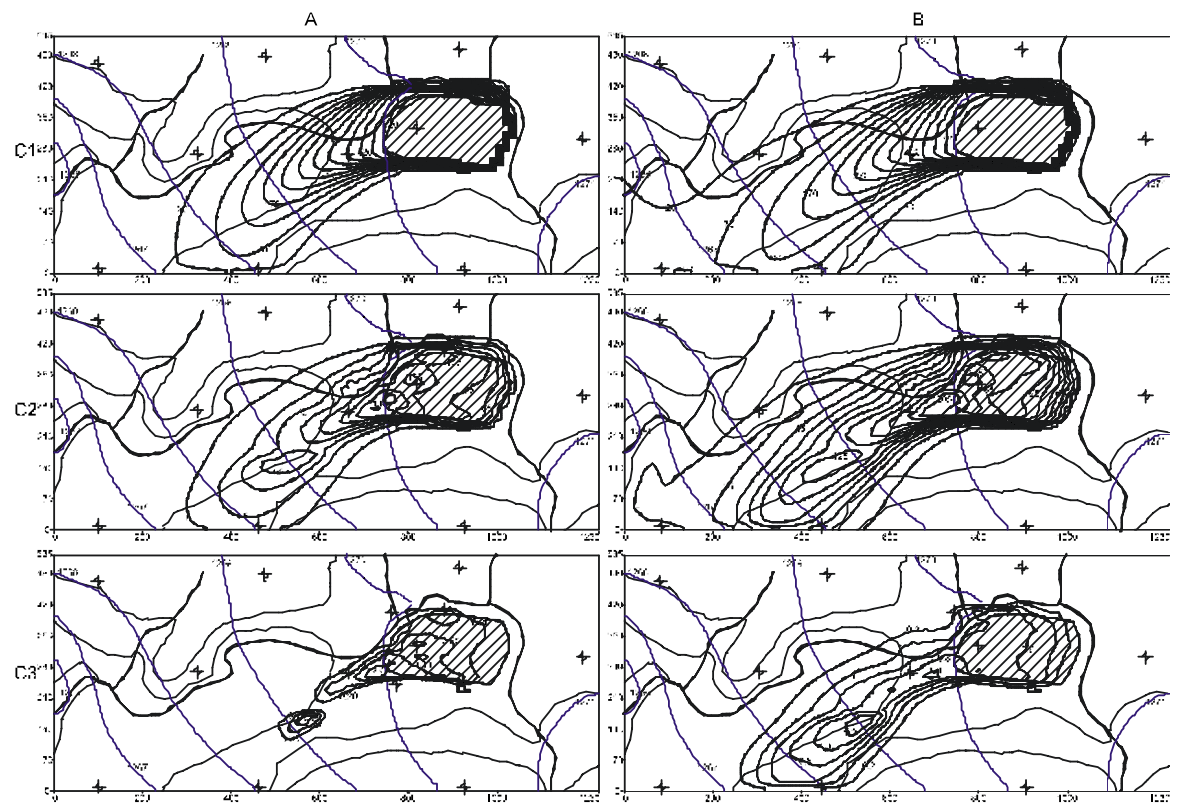

IFGFIDA

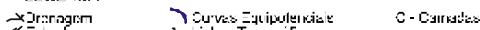

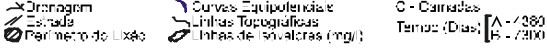

Figura 16 - Frente de contaminação representada por linhas de isovalores de contaminantes para o Cenário 1.

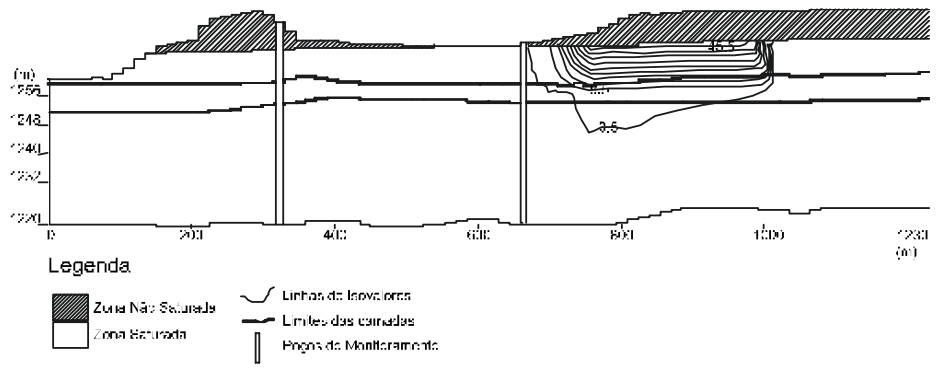

Figura 17 - Seção longitudinal ao Lixão representando a distribuição da pluma de contaminação no Tempo de 1.825 dias para o Cenário 2. (Posição do perfil mostrado na figura 13). 
PALMA, J. B.; ZUQUETTE, L. V. Avaliação do comportamento de frente de contaminação em...

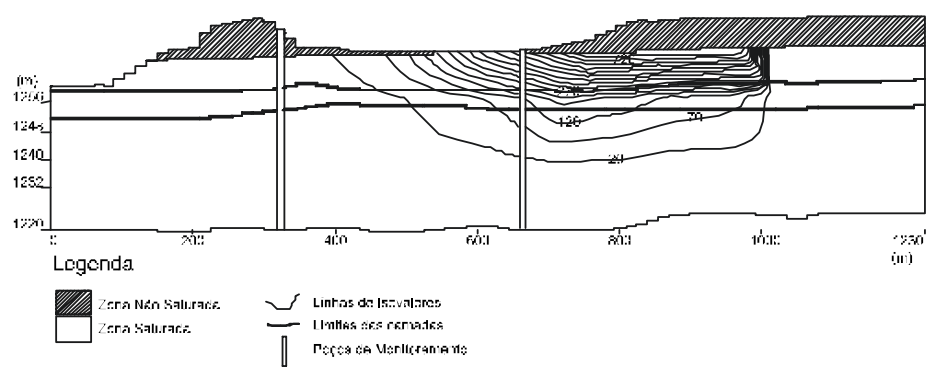

Figura 18 - Seção longitudinal ao Lixão representando a distribuição da pluma de contaminação no Tempo de 7.300 dias para o Cenário 2. (Posição do perfil mostrado na figura 13).
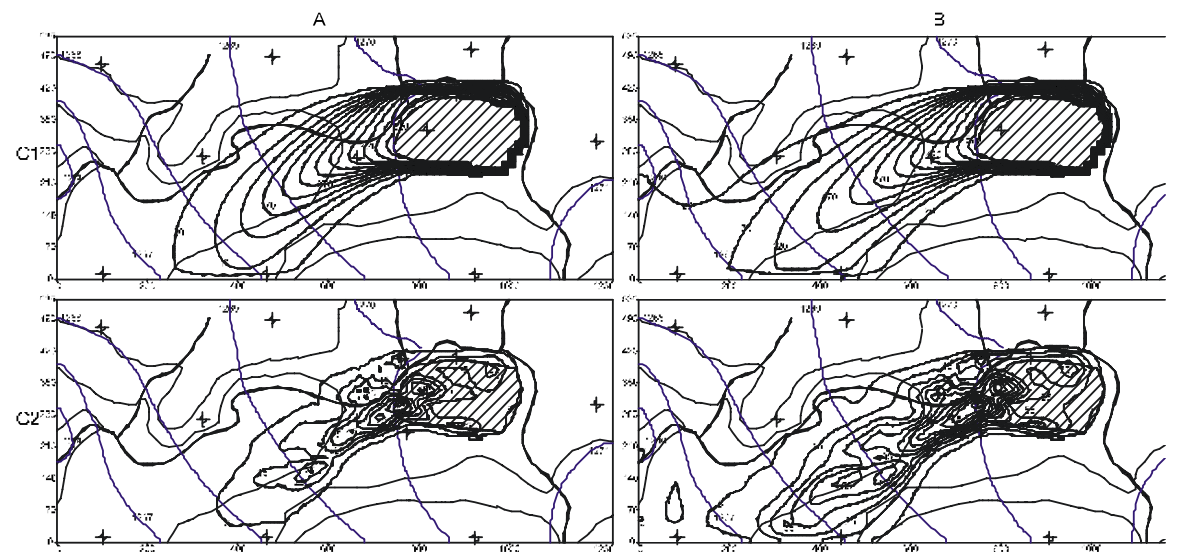

IIGTNDA

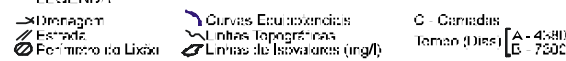

Figura 19 - Frente de contaminação representada por linhas de isovalores de contaminantes para o Cenário 4. 
PALMA, J. B.; ZUQUETTE, L. V. Avaliação do comportamento de frente de contaminação em...

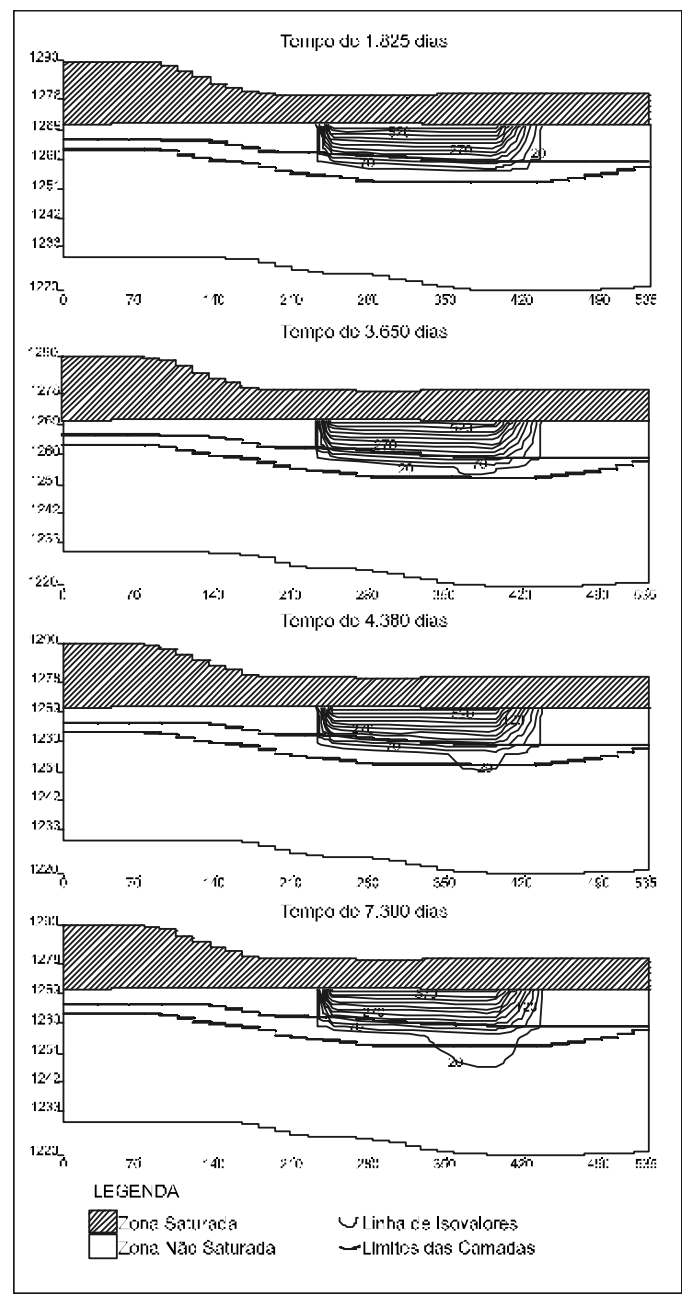

Figura 20 - Perfis longitudinais resultantes do Cenário 4 para os vários tempos. 
PALMA, J. B.; ZUQUETTE, L. V. Avaliação do comportamento de frente de contaminação em...

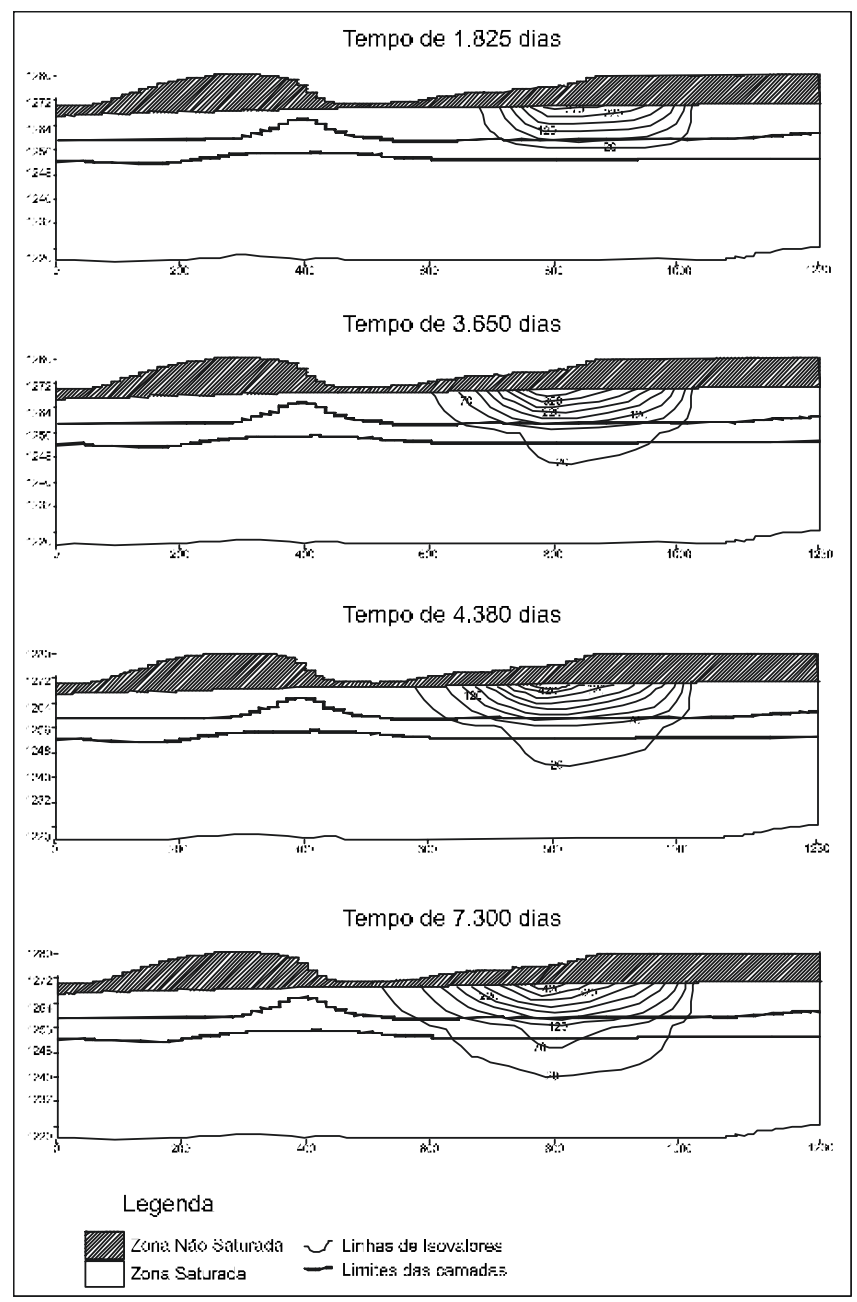

Figura 21 - Perfis longitudinais resultantes do Cenário 5 para os vários tempos. 
PALMA, J. B.; ZUQUETTE, L. V. Avaliação do comportamento de frente de contaminação em...
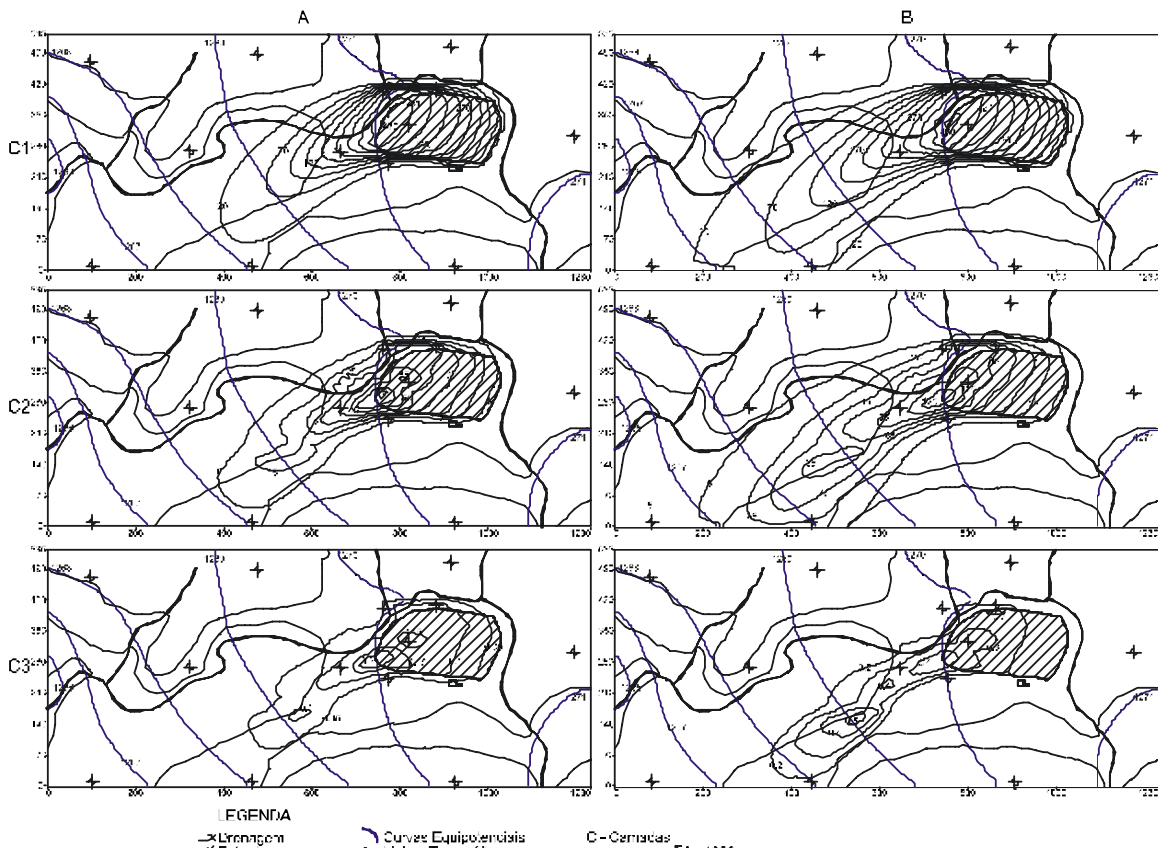

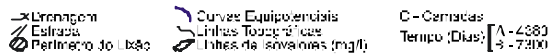

Figura 22 - Frente de contaminação representada por linhas de isovalores de contaminantes para o Cenário 5.

Cenário 3 - As diferenças deste cenário para o cenário 1 , devem-se às razões de dispersividade, o que refletiu nas concentrações que atingiram as camadas 2 e 3 , de ordem superior a $100 \%$. Os comprimentos e larguras da isolinha da camada 1 são similares as do cenário 1, para todos os tempos. Para a camada 2 as larguras e comprimentos são inferiores as do cenário 1 , conforme se observa na tabela 3 .

Cenário 4 - Desde o tempo 1.825 dias, a concentração no topo da camada 3 é superior a 20 ppm e atinge 80 ppm em 7.300 dias. Para a camada 2 as concentrações variam de 150 a 200 ppm, para os tempos de 1.825 a 7.300 dias, respectivamente (figura 19). As larguras e comprimentos para as isolinhas mínimas, para o tempo de 7.300 dias, para as camadas 1 e 2 são 328 , $951 \mathrm{~m}$ e 322 e $781 \mathrm{~m}$, respectivamente. A figura 20 apresenta o perfil longitudinal do lixão para o cenário 4.

Em comparação com as informações da figura 8, verifica-se uma compatibilidade geral. Além da compa- tibilidade dos níveis de contaminação, também verificou se uma boa correlação quanto à distribuição espacial e forma de distribuição dos contaminantes no tempo.

Cenário 5 - Para as mesmas condições do cenário 1 , e fonte com volume total constante, os resultados diferem do cenário 1 na forma de distribuição das isolinhas, nos valores das concentrações para as $3 \mathrm{ca}$ madas. Para a camada 3 a concentração atinge 70 ppm para o tempo de 7.300 dias, e o valor máximo no topo da camada 1 foi de $370 \mathrm{ppm}$, também para 7.300 dias, valores inferiores em $50 \%$ aos obtidos no cenário 1 (figura 21). As dimensões das isolinhas mínimas para o tempo de 7.300 dias são 757 e $290 \mathrm{~m}$, e 742 e $312 \mathrm{~m}$, para as camadas 1 e 2, respectivamente (figura 22).

Cenário 6 - Quando comparado com o cenário 2, que utiliza os mesmos parâmetros com exceção do tipo de fonte, verifica-se de uma maneira geral uma atenuação das concentrações, principalmente nos níveis 


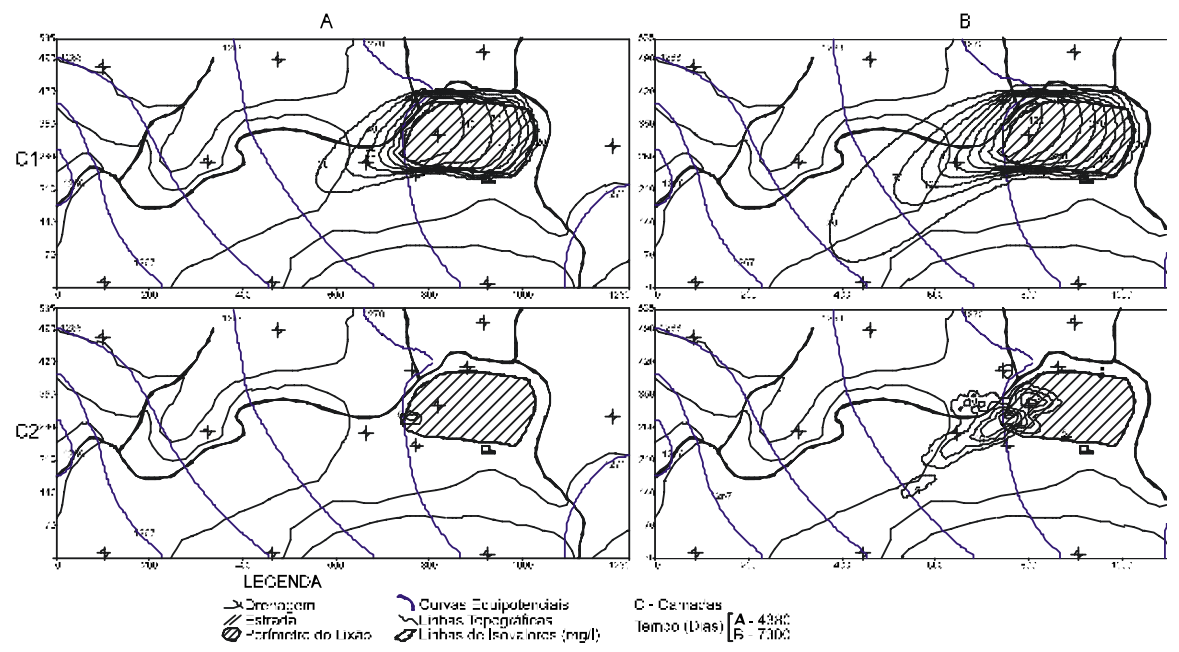

Figura 23 - Frente de contaminação representada por linhas de isovalores de contaminantes para o Cenário 8.

de concentração na camada 3 e no comprimento da frente. Até o tempo de 4.380 dias as concentrações que atingem as 3 camadas são inferiores às concentrações observadas no cenário 2, aumentando para o tempo de 7.300 dias, atingindo $50 \%$ dos valores atingidos pelo cenário 2.

Cenário 7 - Em relação ao cenário 3 , a principal diferença reflete-se nas dimensões atingidas para as isolinhas mínimas nos diferentes períodos, conseqüentemente na forma geral das frentes, e nas concentrações na camada 2 devido ao tipo de fonte simulada.

Cenário 8 - Com base nas condições resultantes da simulação apresentadas na tabela 3 , verifica-se que somente após 20 anos (7.300 dias) a frente atinge a camada 3 significativamente. As figuras 23 e 24 representam, respectivamente, o mapa da frente de contaminação e o perfil resultante desta simulação.

As variações dos valores de dispersividade longitudinal e suas razões verticais e horizontais não afetaram as características da frente de contaminação com a intensidade esperada, em função dos valores elevados da velocidade média de percolação e das dimensões das camadas. Os cenários 5 a 8 apresentam resultados que não são considerados compatíveis com os da eletroresistividade, devido aos seguintes aspectos:
1 - As formas da concentração máxima na camada 1 difere acentuadamente da obtida pela geofísica;

2 - As concentrações máximas para as 3 camadas são abaixo dos valores obtidos pela geofísica.

Cenário 9 - Com base nas informações contidas na Tabela 3 verifica-se que as concentrações para a camada 2 sofrem um aumento rápido depois do tempo de 3.650 dias. Comparados os cenários 2 e 9 verificase que as diferenças podem ser observadas em todos os períodos simulados, seja em relação às dimensões ou quanto às intensidades, principalmente, para as camadas 2 e 3. Para esta condição de fonte a sorção tem efeito significativo no transporte de poluentes.

Cenário 10 - As concentrações que atingem a camada 3 são inferiores as do Cenário 1 refletindo a influência do valor da dispersividade longitudinal (figuras 25 e 26 ).

Cenário 11 - Os valores das concentrações que atingem o topo de cada camada é semelhante aos do cenário 10 . Os valores de sorção considerados não afetaram o transporte devido aos valores elevados de dispersividade e da velocidade linear média de percolação. 
PALMA, J. B.; ZUQUETTE, L. V. Avaliação do comportamento de frente de contaminação em...

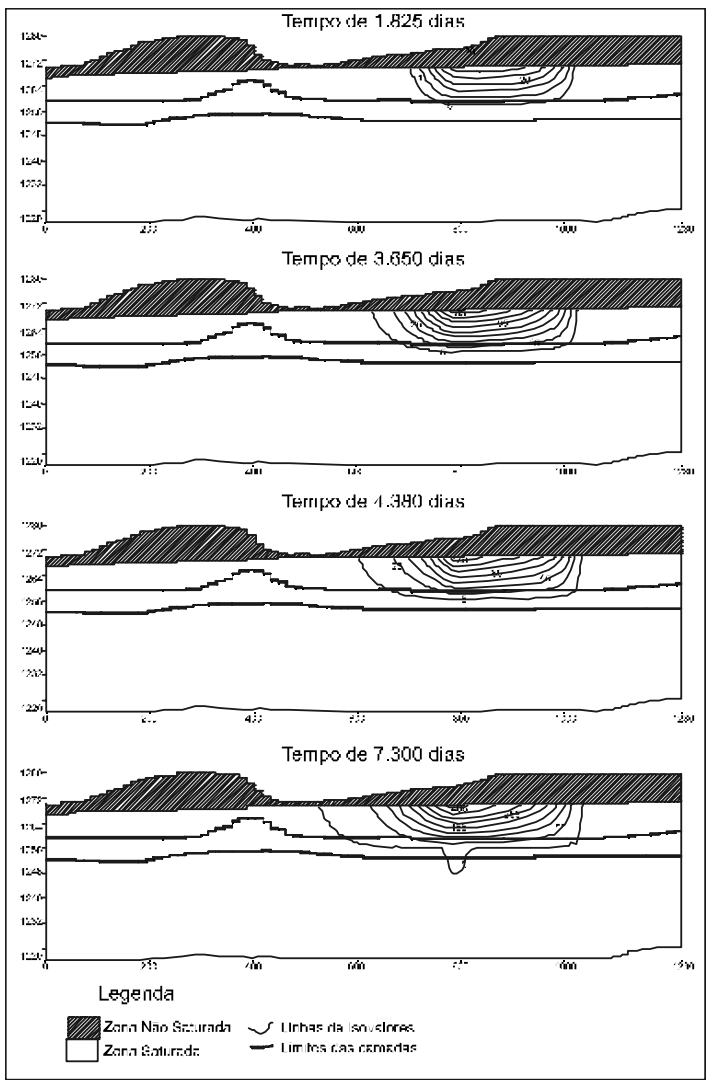

Figura 24 - Perfis longitudinais resultantes do Cenário 8 para os vários tempos. 

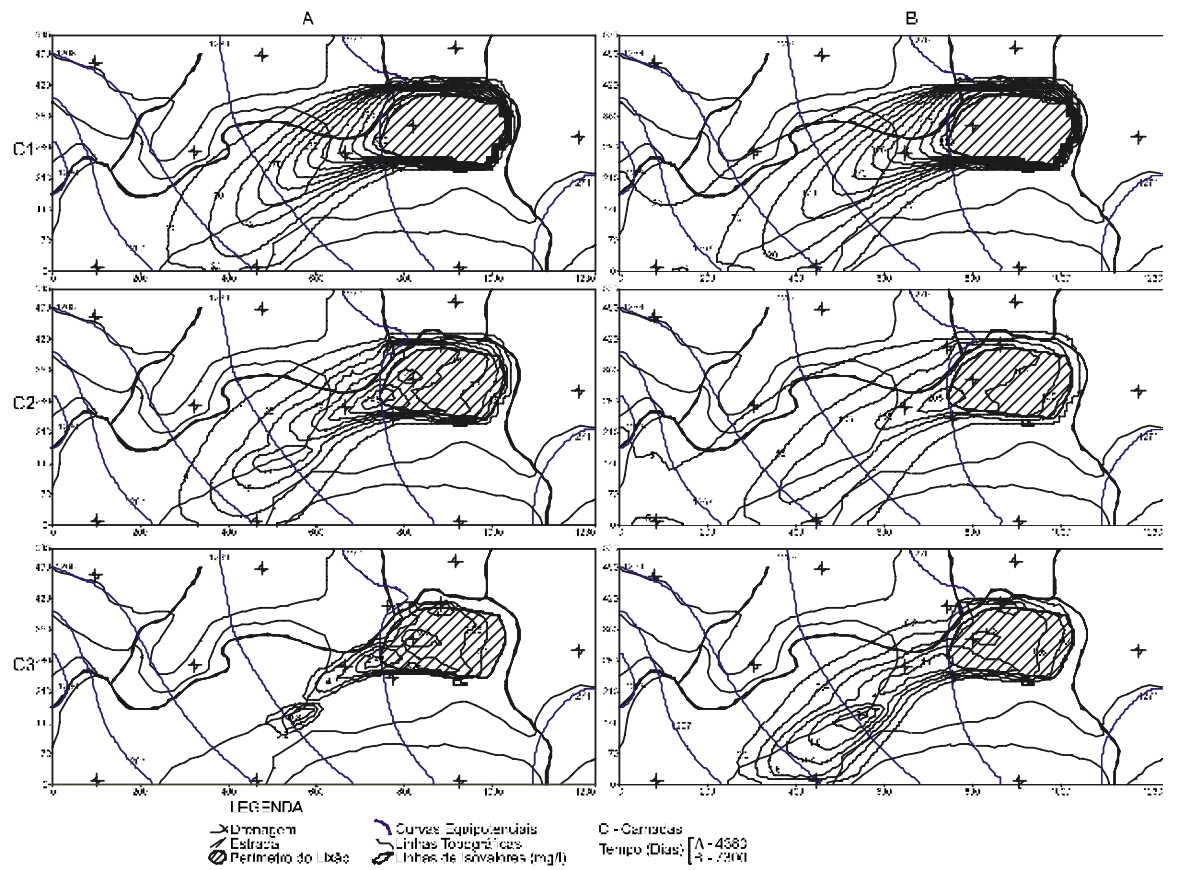

Figura 25 - Frente de contaminação representada por linhas de isovalores de contaminantes para o Cenário 10

Os cenários 1, 3, 4, 10 e 11 consideraram o mesmo tipo de fonte, sendo possível avaliar que o cenário 4 é o que tem os resultados mais compativeis com os obtidos pela eletroresistividade, conforme figuras $19 \mathrm{e}$ 20. Os resultados dos cenários 10 e 11 são os que produzem maiores dimensões em função dos valores das dispersividade longitudinal e das razões entre dispersividade longitudinal e dispersividade horizontal e vertical, como representados nos perfis e mapas das figuras 25 e 26. Entre os cenários 1 e 3 verifica-se o efeito dos valores de dispersividade, principalmente em relação à profundidade (figuras 16 e 24).

Quanto aos cenários 5, 6, 7 e 8 se verificam que as condições do cenário 5 favorecem o transporte enquanto no cenário 8 os efeitos da sorção diminuem a extensão da frente de contaminação, assim como do nível de contaminação no topo da camada 3. Quanto às dimensões das frentes de contaminação são muito semelhantes, conforme se observam nos mapas das figuras 22 e 23 .

\section{CONCLUSÕES}

Como observado por Neuman (1990), o valor de dispersividade longitudinal, quando considerado em modelos numéricos, varia em função da escala do estudo, da definição de zonas homogêneas espacialmente, das características hidráulicas (que são consideradas isotrópicas) diminuindo as extensões e os valores dos coeficientes de dispersividades, ou seja, o detalhamento em termos da condutividade hidráulica diminui o efeito da escala sobre a dispersividade. Desta maneira, trabalhos de investigação geológica - geotécnica que buscam detalhar as camadas com heterogeneidade específica são fundamentais, pois permitem associar parâmetros obtidos em estudos laboratoriais.

O comportamento diferenciado da frente de poluição nas 3 camadas, indica que poços de monitoramento devem ser executados buscando favorecer 
PALMA, J. B.; ZUQUETTE, L. V. Avaliação do comportamento de frente de contaminação em...

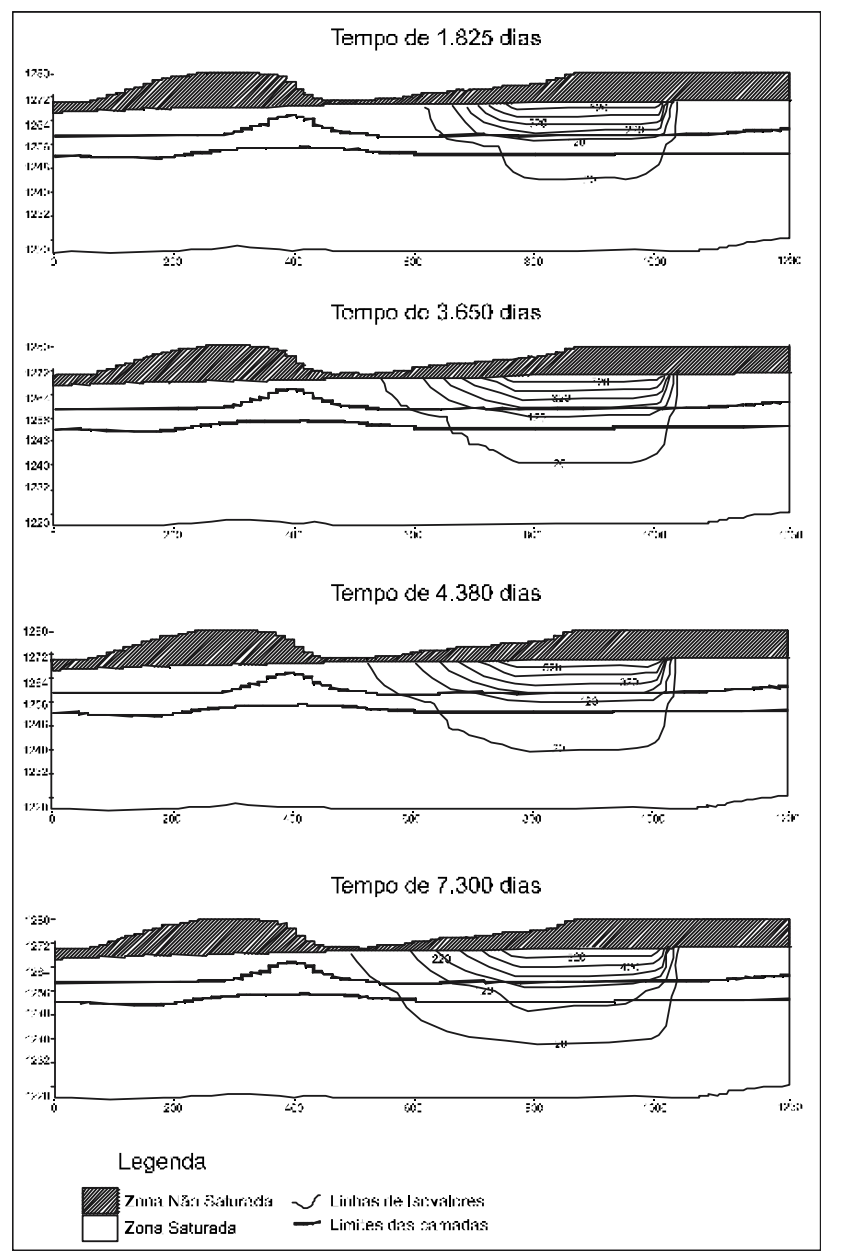

Figura 26 - Perfis longitudinais resultantes do Cenário 10 para os vários tempos. 
PALMA, J. B.; ZUQUETTE, L. V. Avaliação do comportamento de frente de contaminação em...

Tabela 1 - Características Geológicas e Geotécnicas das camadas de materiais inconsolidados e rochosos, adotadas para a modelagem.

\begin{tabular}{|c|c|c|c|c|}
\hline \multirow{2}{*}{$\begin{array}{c}\text { Dados } \\
\text { Utilizados }\end{array}$} & \multicolumn{3}{|c|}{ Camadas } & \multirow[b]{2}{*}{ Base** } \\
\hline & 1 & 2 & 3 & \\
\hline Materiais & Fesidual & Residual & Reliquiar & Rocha \\
\hline Condutividade hidráulica (m/s) & $1.2 .10^{-4}$ & $1.10^{5}$ & $1.10^{-7}=$ & $5.4 .10^{-1}$ \\
\hline Porosidade Total & 0.38 & 0.36 & 0.3 & 0.3 \\
\hline Parosidade Cfetiva & 0.3 & 0.25 & 0.2 & 0.2 \\
\hline Precipitaçäo (mm/yr) & & 1700 & & \\
\hline Recirga (mm/yr) & & 340 & & \\
\hline Capacidade de campo $\left(\mathrm{m}^{3} / \mathrm{m}^{i}\right)$ & & 0.19 & & \\
\hline $\begin{array}{l}\text { Armazenabilidade (Storage) } \\
\left(\mathrm{m}^{3} / \mathrm{m}^{3}\right)\end{array}$ & & 0.0001 & & \\
\hline Concentração constante (mg/L) & & 500 & & \\
\hline
\end{tabular}

* Dados obtidos do trabalho de Carlstron Filho et al. (1978).

** Dado não utilizado na modelagem.

Tabela 2 - Parâmetros de tempo e valores de concentração para o cenário 2.

\begin{tabular}{|cc|c|}
\hline Nivel & Tempo (dias) & Concentracajo (mg/L) \\
\hline 1 & $0-365$ & 50 \\
2 & $365-1825$ & 100 \\
3 & $1825-3650$ & 200 \\
\hline 4 & $3650-4380$ & 500 \\
\hline 5 & $4380-7300$ & 800 \\
\hline
\end{tabular}

Tabela 4 - Concentrações máximas, para o topo de cada camada, nas diferentes condições de simulação e tempo simulados.

\begin{tabular}{|c|c|c|c|c|c|c|c|c|c|c|c|}
\hline \multirow[t]{2}{*}{ Cenárizs } & \multirow{2}{*}{$\begin{array}{l}\text { Congr } \\
\text { cals }\end{array}$} & \multicolumn{4}{|c|}{ Tarros (dias) } & \multirow[t]{2}{*}{ Geráric } & \multirow{2}{*}{$\begin{array}{l}\text { Cama- } \\
\text { das }\end{array}$} & \multicolumn{4}{|c|}{ Ternpe (idizs) } \\
\hline & & $18 \% 5$ & 3650 & $\angle \mathrm{WBO}$ & 7390 & & & $18 \% 5$ & 3650 & $\angle 390$ & 7350 \\
\hline \multirow{3}{*}{1} & ? & $56 \% 1$ & 5 fill & $5 \mathrm{fiC}:$ & 570 & \multirow{3}{*}{$\ddot{0}$} & 1 & $17 \|$ & $27:$ & 3ग्I & $4[: 5$ \\
\hline & $y$ & $20 \%$ & ग'गा & $2 \%$ & 270 & & 7 & प9: & 70 & 70 & 205 \\
\hline & 3 & 8G: & 50 & 126 & 170 & & 3 & $0 \%$ & 20 & 20 & 20 \\
\hline \multirow{3}{*}{2} & 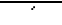 & 95 & BII & 506 & 720 & \multirow{3}{*}{9} & 1 & 100 & 185 & 455 & 720 \\
\hline & 7 & 20 & 60 & 145 & 270 & & 2 & $3 \mathrm{C}$ & 45 & 105 & 290 \\
\hline & 3 & 5 & 20 & 45 & 150 & & 3 & 0 & ] & 5 & 70 \\
\hline \multirow{3}{*}{3} & ' & SPI) & SRII & Bllc: & hilo & \multirow{3}{*}{111} & 1 & SPII & $5 \%$ & 5III & 460 \\
\hline & $y$ & 13!) & "hll & $17 \mathrm{C}$ & 170 & & 7 & 2श्1 & 2W: & 2ग्या & 240 \\
\hline & 3 & 90 & 50 & 60 & $\theta 0$ & & 3 & $2 \mathrm{C}$ & $\theta 0$ & 20 & 120 \\
\hline \multirow{3}{*}{4} & ' & SPI) & $54 I I$ & Bllc: & hiflo & \multirow{3}{*}{11} & 1 & 52II & $5 \%$ & 5.'II & רEO \\
\hline & 7 & 15') & "ㅋII & $196:$ & 210 & & 9 & 1211 & 296 & यश्गा & 240 \\
\hline & 3 & 90 & 40 & 50 & 80 & & 3 & 90 & $\theta 0$ & 20 & 120 \\
\hline \multirow{3}{*}{ t. } & 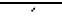 & 2/1 & 3211 & 326 & 370 & \multirow{3}{*}{ Média } & 1 & 323,16 & לא, 3699 & $\angle 44,09$ & 524,5ll \\
\hline & 2 & $7 G$ & 221 & 120 & 170 & & 2 & $1115, C 0$ & 125,91 & $142, / 3$ & 202,27 \\
\hline & 3 & 0 & $\angle 0$ & 50 & 70 & & 3 & 5,02 & 36,36 & 48,18 & 80,40 \\
\hline \multirow{3}{*}{ b } & ? & $\mathrm{3C}$ & 70 & 129 & 320 & \multirow{3}{*}{$\begin{array}{l}\text { Desvio } \\
\text { Pasiådo }\end{array}$} & 1 & $211 /, 49$ & 181,51 & $149, / 1$ & $14 \lambda^{\prime} 43$ \\
\hline & 7 & 5 & 20 & 40 & 120 & & 7 & $20,7 b$ & 77,23 & 56,31 & 52,80̈ \\
\hline & 3 & 0 & 5 & 0 & 40 & & 3 & 23,55 & 27,67 & 36,26 & 52,92 \\
\hline \multirow{3}{*}{7} & ' & 250 & 320 & 350 & 350 & & & & & & \\
\hline & 2 & $7 \mathrm{C}$ & 70 & 70 & 120 & & & & & & \\
\hline & 3 & 0 & 20 & 20 & 30 & & & & & & \\
\hline
\end{tabular}




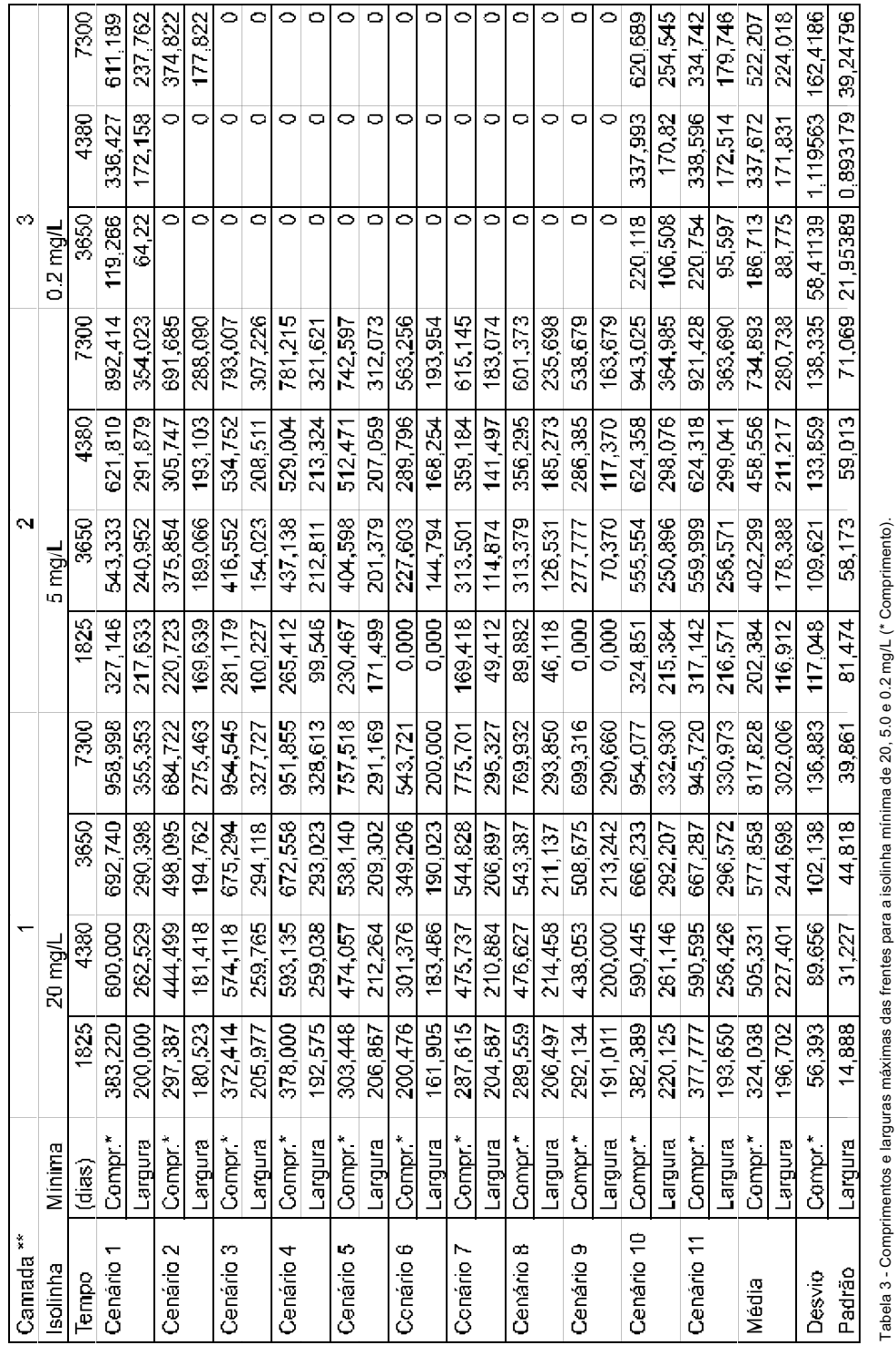


PALMA, J. B.; ZUQUETTE, L. V. Avaliação do comportamento de frente de contaminação em...

amostragens em diferentes profundidades no domínio da zona saturada.

Quando se comparam os cenários em função do tipo de fonte, observa-se que os cenários que consideraram fonte constante $(1,2,3,4,9,10$ e 11) representaram melhor a situação real, tanto em termos de distribuição espacial quanto em valores de intensidade.

Os resultados obtidos a partir das condições do cenário 4 foram os que melhor compatibilidade apresentaram com os dados apresentados pela eletroresistividade, tanto em relação à distribuição espacial quanto à forma de distribuição dos contaminantes no tempo. Esta simulação considerou todos os parâmetros do cenário 1 acrescentando o mecanismo de sorção (segun- do a Isoterma de Langmuir), observa-se desta forma, que embora o transporte pela advecção e dispersão tenha maior importância, a sorção permite aproximar as simulações da condição natural.

\section{AGRADECIMENTO}

Os autores agradecem o apoio financeiro da Coordenação de Aperfeiçoamento do Pessoal de Nível Superior (CAPES) e da Fundação de Amparo à Pesquisa do Estado de São Paulo (FAPESP № Processo 00/ 03027-7) imprescindíveis à realização deste trabalho. Assim como, aos assessores do Boletim Paranaense de Geociências que analisaram o artigo e propuseram modificações que o tornaram mais adequado.

\section{REFERÊNCIAS}

BURNETT R.D. \& FRIND E.O. 1987. An alternating direction Galerkin technique for simulation of groundwater contamination transport I three dimensions, 2: dimensionally effects. WaterResources Research, 23(4):695-705.

CARLSTRON FILHO C.; CORRÊA FILHO D.; BOTTURA J.A. 1978. Caracterização Hidrogeotécnica baseada em dados piezométricos e características hidrodinâmicas do maciço da mina de Urânio Osamu Utsumi, Poços de Caldas. In: Congresso de Geologia de Engenharia, 2, Associação Brasileira de Geologia de Engenharia, Anais... 2: 297-309.

ELIS V.R. 1998. Avaliação da Aplicação de métodos elétricos de prospecção geofísica no estudo de áreas utilizadas para disposição de resíduos. Unesp, Rio Claro, São Paulo, Tese de Doutorado em Geociências e Meio Ambiente, IGCE, 264 p.

FREEZE R.A. \& CHERRY J.A. 1979. Groundwater. Englewood Cliffs, New Jersey, Prentice Hall, Inc. 604 p.

GELHAR L.W.; WELTY C.; REHFELDT K. 1992. A critical review of data on field - scale Dispersion in Aquifers. Water Resources Research, 28(7): 1955-1974.

.; MANTAGLOU A.; WELTY C.; REHFELDT K.R. 1985.

A review of field scale physical solute transport process in saturated and unsaturated porous media. EPRI rep. EA -4190, Elec. Power Res. Inst., Palo Alto, Calif.

GEOLOGICAL SOCIETY. 1990. Tropical residual soil. The Quartely Journal of Engineering Geology, 23(1).
KNOPMAN D.S.; VOSS C. 1987. Behavior of sensitivities in the One - Dimensional Advection - Dispersion equation: Implications for Parameter Estimation of Sampling Design. Water Resources Research, 23(2): 253-272.

MCDONALD M.G. \& HARBAUGH, A.W. 1988. A modular threedimensional finite-difference groundwater flow model. US. Geological Survey Techniques of water-resources investigations, Book 6. Chap. Ai, 586 p.

MEJU M.A. 2000. Geoeletrical investigation of old/abandoned, covered landfill sites in urban areas: model development with a genetic diagnosis approach. Journal of Applied Geophysics, $44,115-150$

NEUMAN S.P. 1990. Universal Scaling of Hydraulic conductivities, and dispersivities in geologic media. Water Resources Research, 26(8): 1749-1758.

OLSTHOORN T.N. 1999. A comparative review of analytic and finite models used at the Amsterdam Water Supply. Journal of Hydrology, 226, 139-143.

SPARKS D.L. 2001. Elucidating the fundamental chemistry of soils: past and recent achievements and future frontiers. Geoderma, 100, 303-319.

WINSTON R.B. 1999. MODFLOW - related freeware and shareware resources on the internet. Computer \& Geosciences, 25, 377-382.

ZHENG C. 1992. A modular Three-dimensional transport model. Golden. CO: International Groundwater Modelling Center. IGWMC - TPS 07. p. 6-32. 